The Relationship between Kitwood's Model of Needs and a Student’s Music Therapy Practice in an Acute Assessment Unit for People Living with Dementia and Mental Health Issues

An exegesis presented in partial fulfilment of the requirements for the degree of

\title{
Masters
}

in

\section{Music Therapy}

At the New Zealand School of Music, Massey campus,

New Zealand.

Maharani Allan 


\begin{abstract}
This study focused on reviewing a student's music therapy practice at an acute assessment unit for people living with dementia and mental health issues, finding links between the placement philosophy, and new ideas about practice. Kitwood's (1997) book on personhood and the needs of people who are living with dementia and other mental health issues appeared to resonate with the student music therapists' practice. This was supported by the active use of his model of needs by nursing staff at the placement. Investigations looked specifically at Kitwood's model of needs; how music therapy links with his philosophy and how interventions during practice connected to those needs. The data was draw from descriptive clinical notes using secondary analysis. The rich qualitative data was analysed using deductive and inductive methods. Findings are presented under Kitwood's model of needs, forming the five categories for the study. The main themes within these categories were then summarised and explanations given under both Kitwood's model of needs and music therapy interventions used to meet them. Though the findings are qualitative, specific to this study and not necessarily generalisable, several links within music therapy practice, and nursing practice revealed the importance and need for more person-centred individualised care programmes for patients in mental health settings.
\end{abstract}




\section{Acknowledgements}

I wish to acknowledge the support and guidance given to me during this research by my supervisors: Melissa Garber, Julie Whitewood and Sarah Hoskyns, your encouragement and confidence in me encouraged my growth and self-belief.

My appreciation is warmly extended to the staff, clients and family at the assessment unit at which my research project was based, especially to the support and collaboration of Sue Robinson who made me feel so welcome.

To my fellow classmates I wanted to say how helpful and supportive you have been on this sometimes frustrating and emotional journey. We got there!

Finally a big thank you goes out to my family who always believed I could do it, no matter what stood in the way.

And last but certainly not least, to my soon-to-be husband Ants Heath, for all the coffees, hugs and loving support you have given me. I never would have been able to do it without you. 


\section{Table of Contents}

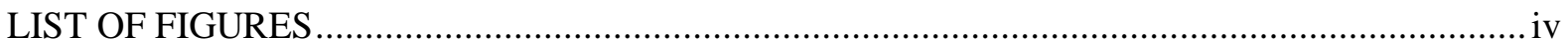

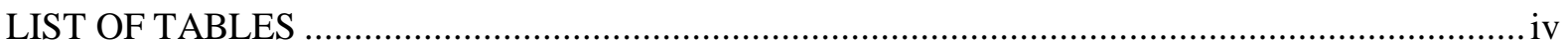

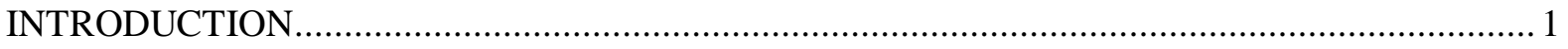

Implications for mental health care in New Zealand ................................................................ 2

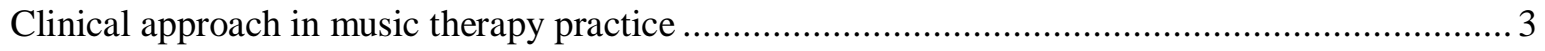

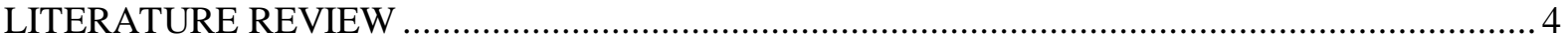

Changes to medical approach in later nursing care .................................................................. 4

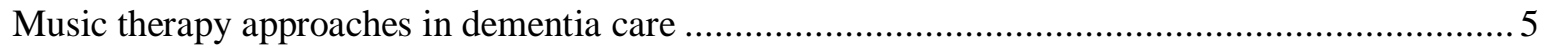

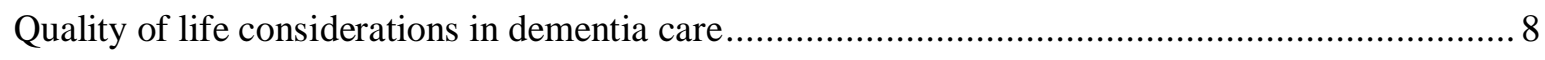

Further reflections on Kitwood's theoretical approach............................................................ 9

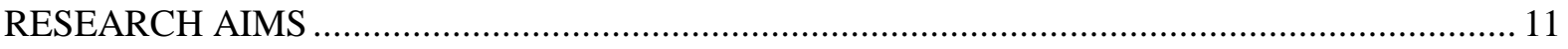

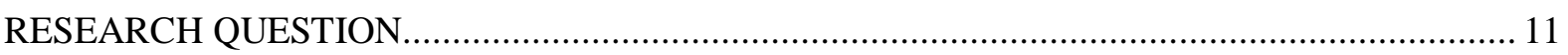

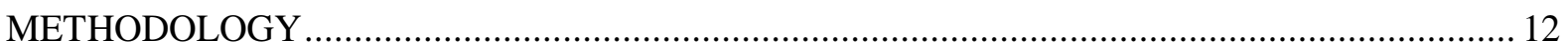

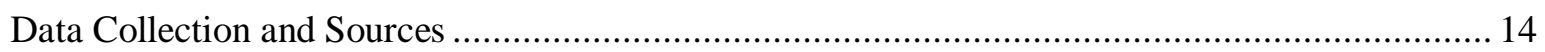

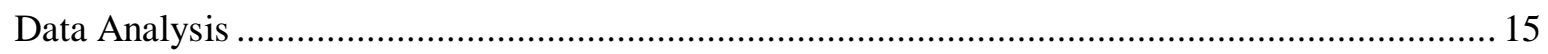

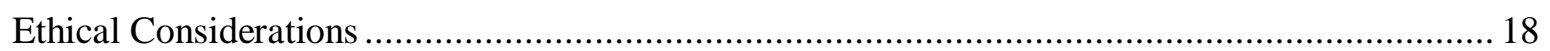

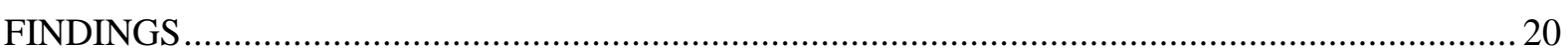

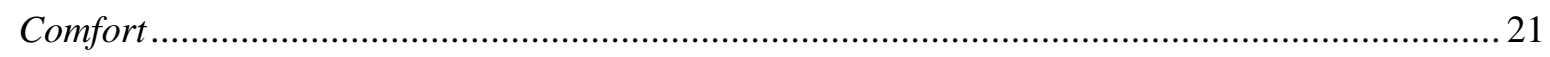

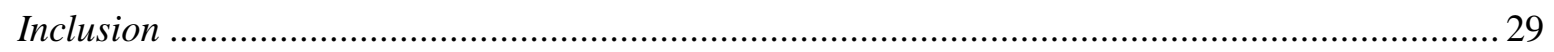

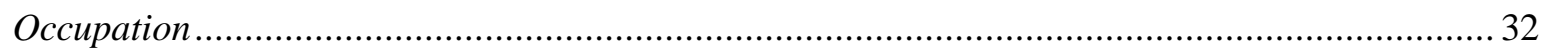

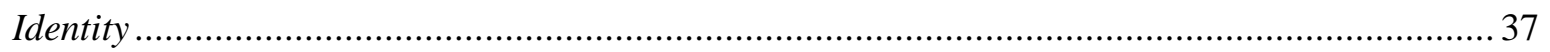

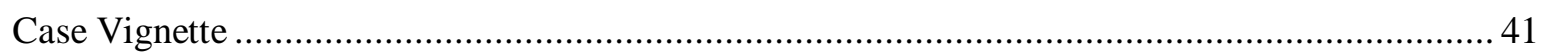

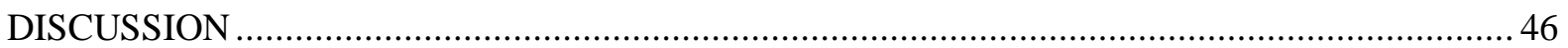

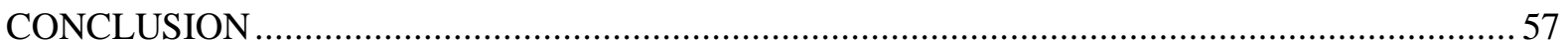

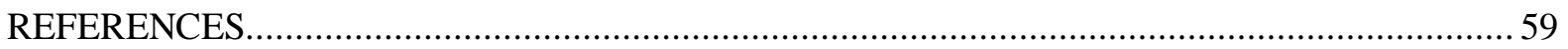

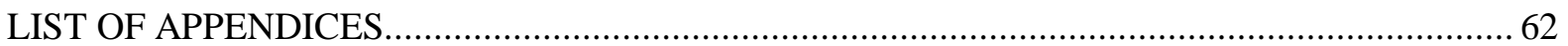




\section{LIST OF FIGURES}

Page

Figure $1 \quad$ Kitwood's model of psychological needs

Figure 2 Mind-map of analysis process

\section{LIST OF TABLES}

Page

Table 1 Example of deductive analysis using Kitwood's comfort need

Table 2 Braun and Clarke’s (2006) phases of thematic analysis

6 


\section{INTRODUCTION}

This research is based on the secondary analysis of clinical notes made during a second year placement at an acute assessment unit for people living with dementia and mental health issues. The short-term assessment unit focused on stabilising conditions and ensuring patients were transitioned into appropriate facilities and levels of care. Patients were admitted primarily for an assessment of dementia, however many had other mental health issues, some associated with the syndrome, others unrelated. In New Zealand, dementia in all its various forms, are defined and provided for under the Mental Health Service. In some cases dementia was ruled out during the assessment; however this was considered the predominant condition for clients in the ward.

My first goal in arriving at the unit was to find appropriate ways to fit music therapy sessions into a setting which had a significant medical and nursing focus. As these factors were considered, questions about an appropriate model of care and the need for a person-centred holistic framework arose. My role in the facility was to look at how music therapy might best assist in relieving and working through some of the issues clients might face in this new hospital environment and help them on their journey through their mental illness.

An article by UK music therapist Simpson (2000) linked creative music therapy with some theoretical ideas of Kitwood in a case study on a person with dementia. This article became my first insight into a person-centred practice of care and resonated with my personal perspectives of a holistic and humanistic approach to music therapy. Kitwood's ideas on personhood and model of needs were supported by the facility's philosophy and were in active use by nursing staff, thus validating further investigations. 
Looking back at the clinical notes I used a deductive and inductive thematic analysis to see how Kitwood's model of needs ${ }^{1}$ might relate to my practice. I wanted to use Kitwood's model of needs to better understand the needs of people I was working with and how music therapy may meet them. By investigating the relationship between the Kitwood's model and music therapy I hoped to extend music therapy and nursing knowledge by generating new ideas on a need based practice and care.

\section{Implications for mental health care in New Zealand}

Like many other countries in the world, New Zealand has an aging population. We face an increasing and proportionately older population that will have different and perhaps complex health and disability issues over the next 10 to 20 years (NZMOH, 2004, p. 129). Post World War II baby boomers will reach retirement age during this period and this could have a significant impact on rates of dementia diagnoses in New Zealand. Currently there are approximately 40,000 New Zealanders who are living with dementia and it is estimated that by 2026 over 77,000 New Zealanders are expected to be diagnosed with it (Laugesen, 2011). Dementia is defined as a clinical syndrome characterised by loss of cognitive and emotional abilities, which are enough to interfere with daily functioning and quality of life (NZMOH, 2004). There are over 55 illnesses which can cause dementia and many people have been shown to suffer social, material and personal losses from having dementia. Many lose self esteem, social skills and personhood ${ }^{2}$, become depressed and, with severe neurological impairment, also develop physical or mental illnesses (NZMOH, 2002). Dementia is included under mental health service because of the above variety of forms and disabilities it causes. How such a decline becomes evident will depend on the cultural, social and environmental outlook of the individual (Kitwood, 1997). Usually most are displayed through a variety of

\footnotetext{
${ }^{1}$ Please see list of appendices

2 Definition of personhood: "a standing or status that is bestowed upon one human being, by others, in the context of relationship and social being” (Kitwood, 1997).
} 
behaviours, i.e. inability to stay still, aggression, verbal-outbursts and many other symptoms, which in nursing environments are described as disturbing Behavioural and Psychiatric Symptoms of Dementia (BPSD) (Ridder, Wigram, \& Ottesen, 2009). This is an ongoing issue as there is currently no known cure for dementia and rates of reported cases are expected to rise to 120 million worldwide by 2050 (Ridder, et al., 2009). Therefore it is imperative that people living with dementia receive the best care and intervention so that they remain understood, acknowledged and have their needs met as the human beings they are (Bartlett \& O'Connor, 2010). In most settings a medical and pharmaceutical approach is taken, however many drugs have side-effects and in some cases exacerbate symptoms of dementia such as agitation (NZMOH, 2011). Recent research studies have advocated using music therapy interventions and it is generally accepted as a beneficial and cost-effective form of intervention in dementia facilities (Goodall \& Etters, 2005; NZMOH, 2011).

\section{Clinical approach in music therapy practice}

My own approach as a student music therapist was a flexible humanistic approach. I felt sharing music and songs while being open to the changes the client or environment brought to the session would suit the unpredictable setting and diagnosis I was working with. On the ward I had open groups. While we had a set time for group music therapy sessions (one hour in the afternoon, three days a week) both the content and clients changed depending on their needs and medical staff at the time. This also included individual sessions. Improvisation (Wigram, 2004) was an integral method in my practice as it helped me connect with clients who were often living in a moment to moment existence. In this way I felt drawn to a personcentred approach and the opportunities it offered to understand the both clients I was working with and also make connections in building a therapeutic relationships. 


\section{LITERATURE REVIEW}

The literature review sought to investigate the links between nursing care focus and music therapy practice. Therefore nursing, music therapy and Kitwood related articles (from 2000 to present day) were drawn from various databases such as Medline, Scopus, Ovid, PsycINFO, Science Direct, Google Scholar, Voices, and Massey and Victoria University's library catalogues. Key word searches included 'Music Therapy and Kitwood', 'Music Therapy and Dementia', 'Music Therapy and Nursing' and 'Kitwood and Nursing'. Some nursing and Kitwood articles were given to me from staff at the placement. Over 68 articles were collated and read. Due to the number of articles, I will be discussing only some of these here and only those most relevant to the research question, specifically 'music therapy', 'Kitwood', 'dementia' and 'needs'3.

\section{Changes to medical approach in later nursing care}

Nursing articles, prior to Kitwood's publication, point to dementia care commonly following a medical approach and that nursing care plans "did not capture the characteristics of residents values and culture" focusing on the disease rather than the person experiencing it (Wills \& Day, 2008). Kitwood's model of needs looks at what people with dementia most need as human beings. His theory is based on the central belief "that neurological damage alone cannot account for the level of outward decline and impairment” (Sherratt, Thornton, \& Hatton, 2004, p. 10) and that some symptoms are the by-products of the environment and personality not the disease (Kitwood, 1997; Munk-Madsen, 2001). This suggests that nonpharmaceutical interventions may be appropriate to treating people with dementia and mental health issues. This view is also shared by the New Zealand's Ministry of Health Committee who are currently reviewing aspects of care for those living with mental illnesses and

\footnotetext{
${ }^{3}$ Following final examination searches that included 'music for older people' may have produced more information.
} 
dementia (NZMOH, 2002, 2011). They recommend interventions that focus on "specialist psychological interventions" that "aim to promote wellbeing and alleviate psychological concerns” (NZMOH, 2011, p. 24). They suggest that music therapy is an effective therapy under their list of approved services and that best practice should follow international discussions and strategies to respond to the needs of people with this syndrome.

\section{Music therapy approaches in dementia care}

Simpson’s (2000) article on 'Creative Music Therapy, A Last Resort?’ was the first article which made me think about models of care and music therapy. Simpson highlights the use of the model in his creative music therapy practice by presenting a case study of a man with advanced dementia. He claims to use the model because it pays "significantly greater attention to psychological and emotional needs" which is based on the premise that despite disintegrating effects of old age there always remains "a sentient individual” (Simpson, 2000). He also cites the importance of appropriate care due to the rising rates of dementia sufferers, especially care that develops non-verbal interventions which can both "counteract the isolation of a dementing illness and address emotional and psychological needs of the individual” (Simpson, 2000). He describes music as liberating his client from the struggle with words because the intimate quality of music enables two people to "mean the same thing in the same moment" without the need for words, transcending the limitations that people living with dementia face (Simpson, 2000, p. 171). Music also helps people with dementia

make sense of time-flow and event sequences because it has a natural continuity and orientation(Aldridge, 2000). Simpson (2000) uses Kitwood's model of needs to make sense of both his own practice and also his client's needs. Simpson summarises the importance of this relationship as: 
- comfort, because music's consoling power can reach depths of the psyche that far surpass the level that can be reached by words.

- attachment, because the communicative potential of improvised music means that relationship may continue unimpeded by verbal loses.

- inclusion, because the music is created spontaneously and is incomplete with the individual's personal contribution.

- occupation, because participative music-making concentrates the mind, encouraging the development of skill and imagination.

- identity, because to experience oneself in dynamic relationship with another reinforces a sense of self that transcends the debilitation of a mind-dissolving disease. (p. 182)

Nugent (2003) discussed her experiences of groups of people with a diagnosis of Alzheimer's disease and related disorders (ADRDS). Unlike Simpson, she looked specifically at agitation and ways to reduce this behaviour for people in long term care because research suggests that people with a higher rate of decline required more nursing care and that reducing agitation produced a better quality of life (Nugent, 2003). Nugent refers in her paper to other researchers who also suggest that agitation is simply caused by people having unmet needs, "particularly in the areas of communication and social interactions" (p. 64). She goes on to describe how many behaviours can be explained through previous past behaviours and roles. In the management of agitation Nugent referenced some of Kitwood's principles including: "recognising the uniqueness of each individual; the importance of communication and attachments; creating a sense of community; and giving respect to each individual's past” (2003, p. 66). Nugent's work reflects extended ideas of Kitwood's model of needs. She found numerous studies that found "unmet psychosocial needs could contribute to agitation" (Nugent, 2003, p. 69).

In this paper Nugent presented various methods to meet the individual needs clients brought to a group. Nugent's list includes matching the music to the mood and participation level of the group to increase cohesion; knowing 'key' songs that group members responded to, as they can help 'ground' the group; and active methods such as movement and instrumental 
playing as they can often channel psychomotor agitation in a more meaningful way. She concludes that group music therapy, while meeting Kitwood's principles of "creating comfort, a sense of attachment, a feeling of inclusion, a sense of occupation, and validating an individual's past habits, while maintaining a sense of identity”, can also provide opportunities for intimacy, an important aspect for each client within the group (Nugent, 2003, p. 75).

Ridder, along with fellow colleagues, has written many articles on the use of music therapy and dementia and is influenced by Kitwood's personhood model (Ridder \& Aldridge, 2005; Ridder, 2003, 2004, 2011; Ridder, et al., 2009). Her PhD study was on the 'influence of singing for social engagement with people with severe frontotemporal dementia'. She found that there was a lack of research on non-pharmacologic treatments for this group and investigated the use of music therapy for treating secondary symptoms, i.e. psychiatric symptoms, depression, isolation.

Her research on the effects of music therapy on frontotemporal dementia focused on the needs of clients, integrating both qualitative and quantitative data in a flexible research design. Ridder and Aldridge (2005) linked four aspects of music therapy sessions with Kitwood's model of needs describing them as; “constitutional, regulative, dialogical and integrative” (p. 98). She describes how the songs in the 'constitutional' part of the session were used as cues in order to catch the attention the participant. In the 'regulative' part, songs were used to regulate arousal levels, utilising the stimulating or calming effect music has on the human nervous system. In the final section, the 'dialogical' part, songs were used to enhance communication and dialogue by using music therapy techniques such as "holding, containing, validation and empathy”(Ridder \& Aldridge, 2005, p. 101). Similar to what I found with Kitwood's model of needs, Ridder and Aldridge found that only on paper was it possible to differentiate these four steps, as in practice they heavily overlap. They found that 
the emotional undertones in songs made people react emotionally because they can "recognise and identify [ourselves] with parts of it” (pg. 100). Music therapists can use these techniques to bypass functional deficits to make contact and address the psychosocial needs, thus reducing secondary symptoms. Ridder (2005) used Kitwood to summarise her interventions saying that “The heart of the matter (is) acknowledging the reality of a person's emotions and feelings, and giving a response on the feeling level” (p.91).

There have been several articles on links between music, music therapy and medical practice. Goodall and Etters looked at how music is processed by different parts of the brain, and found that it can serve as means of communication for those whose verbal ability has declined. They also found how different elements in music (rhythm, melody, pitch, and vibrations) can access different parts of the brain, particularly the right hemisphere and limbic system, which deal with emotion, and that language and music offer a greater chance of activating intact neurological pathways than using language alone (Goodall \& Etters, 2005). They concluded that the benefits of music "are not limited to enjoyment" but can be used to "improve health and quality of life" in people who are suffering the effects of dementia (Goodall \& Etters, 2005, p. 261).

\section{Quality of life considerations in dementia care}

Quality of life for those living with dementia was the focus for Kitwood's 1997 book 'Dementia Reconsidered'. Dewing claims that Kitwood seeks a “person-centred practice (that) requires healthcare professionals to put the person first and the evidence base for technical or clinical interventions second” (Dewing, 2008, p. 7). Subsequently nursing articles now focus their practice and research on person-centred care because they found that it allowed those present to see the person in the context of their past rather than the context of the care setting, ultimately improving connections between staff and patients and levels of quality of care (Wills \& Day, 2008). Ridder (2009) used Kitwood's personhood theory to 
guide their work because quality of life was a key factor in daily care and research, identifying and prioritising person-centred psychosocial needs as a focus.

Powell (2006) also linked quality of life from Kitwood's model of needs and Aldridge's music therapy research $(2000,2005)$, by saying "it can help improve quality of life and emotional well-being as well as lead to improvements in memory, health and sense of identity” (2006, p. 109). This suggests there is a natural affinity between Kitwood's model of needs, music therapy practice and improvements in quality of life.

Wall and Duffy (2009), also nurses, completed and published a literature review on the use of music therapy for older people with dementia. Instead of seeking to find the neurological effects music had on the brain they sought to understand how music therapy influenced behaviour in older people with dementia. They completed a thematic analysis of the literature in Britain and discovered three themes, "the effects of music therapy on agitated behaviours; music therapy and role of carers; and the positive effects of music therapy on mood and socialization” (Wall \& Duffy, 2010, p. 109). They found that music therapy promoted positive effects in mood and socialisation, and that these positive effects also extended to caregivers. Wall and Duffy conclude that there is a clear need for future research in this area but that ultimately healthcare providers needed to play an active role in the provision of

music therapy which was clearly a "valuable commodity, positively influencing the behaviour of elderly patients with dementia” (Wall \& Duffy, 2010, p. 112).

\section{Further reflections on Kitwood's theoretical approach}

A review of nursing literature revealed some shared views on Kitwood's book. It also outlined why Kitwood's personhood theory is still relevant today (Dewing, 2008). Dewing explains that this is because Kitwood helped change the cultural and central belief that "persons need to have cognition to be considered and accommodated as persons" (2008, p. 
5), and that although Kitwood favours an anti-medical approach he still accepts the contribution of neuropathology which many other forms of social constructionist explanations do not. This made it a more accessible and less confronting framework to those coming from a medical background while extending society's understanding of dementia and those suffering from it. Dewing (2008) notes one criticism levelled at Kitwood's personhood model was that it is seen as exclusively for the client and did not incorporate others such as staff, carers or families (Dewing, 2008). However, I have found that Kitwood appears to address this in his 'model of needs' section, where he quotes that these needs are "basic needs" (1997, p.81) and that everyone needs them to function as a human. Kitwood did in fact have carers in mind when he wrote his book. He wanted to change long-held perspectives about dementia patient's behaviour and how they are related to the care they received. In this way carers could gain more insight into the reasons behind a behaviour, modify the environment or interaction and change the behaviour.

Kitwood's (1997) book 'Dementia Reconsidered, the person comes first' put forward new ideas on a person-centred model of care. He also developed Dementia Care Mapping (DCM), a new method for carers to evaluate the care of people living with dementia. DCM is based on principles of personhood based on the individual with dementia and aims to enhance the wellbeing of the client through quality of care. Kitwood defines personhood as "the standing or status that is bestowed upon one human being, by others, in the context of relationship and social being” (pg. 8). He implies that recognition, respect and trust are both conditions of personhood and that the failure to do so would have consequences that are "empirically testable” (pg. 8). Kitwood's theory of personhood has come from three main types of discourse: transcendence, ethics and social psychology. Transcendence comes from different cultural theories on the importance of self, spirit and inner nature of a person. Ethical discussion looks at the importance each person has and the principle of respect and rights. 
Social psychology has a primary association with self-esteem, the performance of given roles in social groups and the stability of the sense of self. Kitwood is focused on equality and the rights and needs of those living with dementia. His argument is a moral one and while he champions the rights and needs he also provides some ideas, models and theories on how to improve current care models. He looks at positive person work and provides a Quality of Interaction Schedule ${ }^{4}$, a model of needs, models for caring organisations and the requirements necessary for personhood care. The range of understanding and insight within the book is meant as a sort of 'how-to guide'. I will be focusing specifically on his model of needs while being aware of the personhood concept within which it fits.

\section{RESEARCH AIMS}

The aim of this study was to review a real-life practice to investigate the links between Kitwood's model of needs and music therapy practice. The research focused on Kitwood's holistic model of needs to extend music therapy and other clinicians' knowledge. I hoped to generate ideas on intervention and practice for those working in similar short-term assessment units for people living with dementia and mental health issues.

\section{RESEARCH QUESTION}

How does Kitwood's model of needs relate to a student music therapist's practice in an acute assessment unit for people living with dementia and other mental health issues?

\footnotetext{
${ }^{4}$ Please see list of appendices
} 


\section{METHODOLOGY}

This qualitative research used secondary analysis of data and with Bruscia's outline of theoretical research as a structural framework (Bruscia, 2005b; Epstein, 2010; NZSM., 2011). Qualitative research enables researchers to examine in depth areas of clinical practice and to explore complex data in an open way. Qualitative research worked well with the research design because it was an 'inextricable emergent, personal and interpersonal process'(Bruscia, 2005a, p. 129). This allowed the researcher to be guided by the developing research question, to discover meaning, while still giving space for it to emerge "through the process of discovery” (Bruscia, 2005a, p. 129). As the researcher was also a student it allowed space for continued understanding and learning to occur parallel to the research process.

The qualitative design was also used to ask simple, but reflective questions about the practice, providing rich material for the methods and analysis process (NZSM, 2011). The analysis process was both deductive and inductive, following Braun and Clarke's (2006) flexible approach to thematic analysis. Thematic Analysis is a process of continued re-looking at the data to clarify and understand the meaning within coded extracts. Thematic analysis is useful when dealing with qualitative data as it has similar processes of discovery which made it a clear choice as the analysis design. This process will be described in more detail in the data analysis section.

Secondary analysis was the central approach to framing the research question, data collection and processing used in this study. This kind of analysis has a fairly short history in qualitative research but is similar to Clinical Data-Mining (CDM) as set out by Epstein (2010). Secondary analysis is the process where usual clinical notes or paperwork from a previous practice are used as data sources to theorise about an aspect of practice (NZSM, 2011). Like CDM, secondary analysis makes use of available, rather than original material, what has been generated for clinical rather than research purposes (Epstein, 2010). Secondary analysis is 
especially suited to engaging practitioners and students to reflect about their practice as it is necessary to use the clinical sources as data in the research, effectively making it a practiceexperienced-based research design (Epstein, 2010). Secondary analysis is a particularly suitable process because it allows the researcher to reduce the risk on ethical issues. This is particularly important as changes to a practice style can occur if the research is undertaken at the same time of practice. Because the work and practice had already been concluded there were no direct participants in the research study as was requested in the ethical guidelines for research procedures (NZSM, 2011).

The theoretical approach of the study was partly self-inquiry. I was a student, seeking to understand a practice and appropriate ways of providing therapy within that setting. It was about being aware of my personal perspectives and assumptions in practice. These therapeutic assumptions may have affected my theoretical practice and model of research. However, being aware of my assumptions also made it easier to make choices and evaluate them during the research process. As I was also applying a theory (Kitwood's model of needs) to my data analysis it was necessary to have some understanding of the underpinnings involved in the construct. To ground my understanding I followed Bruscia's steps of philosophical analysis. This is described as importing a philosophical theory or construct into music therapy and then "applying it to a particular theory, practice, or research" (2005, p. 544).

This approach seemed very fitting to my interest in examining Kitwood's established holistic theory about nursing practice and patients with dementia. Through conducting this inquiry there was a possibility that my ideas about music therapy could be developed and expanded by other fields (i.e. medical/nursing), and there was also the possibility that nursing practice could like-wise be influenced by music therapy thinking as indicated in the literature review. By applying a Bruscia’s steps of philosophical analysis and Kitwood’s model I looked at my 
music therapy practice to identify the cause-effect of relationships in practice and to change my perspectives, so that new insights would be gained on the relationship between nursing and music therapy practice.

\section{Data Collection and Sources}

During the practice there was one data source:

- Clinical notes

\section{Clinical Notes}

The clinical notes where compiled directly after each session. The first six months of clinical placement notes were used. The clinical notes were a mixture of individual and group observations written directly after each session. These included staff and family comments, as they occurred, and were compiled in chronological order in data sets of 6 weeks of work. Due to the nature of the facility the clinical notes were based on observations of the sometimes variable participation of different individuals and groups during this period. The first 4 data sets were selected for analysis, as at this point they were the only notes able to be reviewed for secondary analysis.

\section{Inclusion criteria for data}

The only requirement for including data in the study notes that referred to music therapy participants who had, or were there for, a primary assessment of dementia with perhaps other secondary mental health issues. This requirement became necessary part way through the placement when three beds were delegated to patients from wards where dementia was not a primary health issue. This was due to an upgrade at the hospital and a shortage of beds. During the de-identification and analysis stage notes from several clinical sessions were excluded from the study. 


\section{Data Analysis}

Thematic Analysis

Thematic analysis was chosen as the method to identify, analyse and report on patterns or themes across the data set. Thematic analysis is often used for its "theoretical freedom" (Braun \& Clarke, 2006, p. 5) because it has the capacity to organise and describes the data set minimally. It allows a researcher to make sense of a large amount of potentially rich and detailed and complex accounts of data in easier to understand pieces. It has the potential to go further and also interpret various aspects of a research topic and is a rigorous tool for analysing qualitative data as it requires the researcher to constantly review content and meaning within the data. The use of thematic analysis also meant that the research would not need to subscribe to the "implicit theoretical commitments of grounded theory"(Braun \& Clarke, 2006, p. 8) making it more suitable to investigate the relationship between practice and a model of care rather than trying to develop a new theory. It was important this was considered because the theory being applied came from a different field (i.e. psychosocial/nursing), so a deductive approach, central to the research question and analysis needed to be more flexible in outcome.

\section{Data Process}

The data analysis followed a thematic process as set out by Braun and Clarke (2006). This involved looking at the data sets through a range of different stages. A data set was a period of 6 weeks. The first 4 data sets were selected and analysed in continuum using both deductive and inductive thematic analysis approaches. This involved first reading through the 
data and noting ideas on what was occurring then also going through and looking at the ideas through Kitwood's model of needs. Braun and Clarke (2006) listed the phases ${ }^{5}$ as:

1. Familiarising yourself with your data

2. Generating initial codes

3. Searching for themes

4. Reviewing themes

5. Defining and naming themes

6. Producing the report

During the first phase I read and re-read the data, noting down initial ideas and becoming familiar with the contents of each data set chronologically. A mind-map of the analysis process was at this point produced to understand the progression of the analysis procedure ${ }^{6}$. The second phase was to use Kitwood's model of needs; Comfort, Attachment, Inclusion, Occupation and Identity to code sections of the data, becoming my main categories in the analysis. The deductive approach was undertaken using Kitwood's description of each need and summarising and colour coding ${ }^{7}$ sections of the raw data according to the need, for example this was a coding for the need comfort:

\footnotetext{
${ }^{5}$ Please see list of tables for Braun and Clarke's phases of thematic analysis

${ }^{6}$ See list of figures for mind-map of thematic process

${ }^{7}$ See List of Appendices
} 


\begin{tabular}{|l|l|l|}
\hline $\begin{array}{l}\text { "However when I played the } \\
\text { song for him he stopped } \\
\text { talking and stood there next } \\
\text { to my chair watching and } \\
\text { listening." }\end{array}$ & $\begin{array}{l}\text { Comfort - Kitwood defines it in its } \\
\text { original sense and then particularly to } \\
\text { those with dementia. Comfort is likely } \\
\text { to be especially important when a } \\
\text { person is dealing with a 'sense of } \\
\text { loss'(bereavement, failing abilities, } \\
\text { ending of long established way of life). } \\
\text { Comforting a person provides a kind of } \\
\text { warmth and strength which might } \\
\text { enable them to remain in one place } \\
\text { when they are in danger of falling } \\
\text { apart. }\end{array}$ & $\begin{array}{l}\text { Coded as: Calming his anxiety, } \\
\text { allowing him to remain in one } \\
\text { place. }\end{array}$ \\
$-\quad \begin{array}{l}\text { It soothes (pain and sorrow) } \\
-\quad \begin{array}{l}\text { Calms anxiety } \\
\text { clovides security (through }\end{array}\end{array}$ & \\
& $\begin{array}{c}\text { Gives support, warmth, } \\
\text { strength (for remaining in } \\
\text { one piece) }\end{array}$ & \\
& $\begin{array}{l}\text { Particular features of dementia: } \\
\text { The need for comfort is intense in } \\
\text { moments of parting and heightened } \\
\text { sexuality. }\end{array}$ & \\
& & \\
\hline
\end{tabular}

Table 1: Example of deductive analysis using Kitwood's comfort need.

In the third phase the data was reviewed again to find the meanings within each example of coded extract, collating them all in a spreadsheet to investigate themes relevant to each category/need. Once the themes had been collated across the first three data sets the fourth phase began. This involved a two level process where the first double checked the themes in relation to the coded extract and then using the $4^{\text {th }}$ data set refined them and further validate what each code was demonstrating within the practice. The main question that was asked during all of these phases was "How does Kitwood's (need i.e. Comfort, Attachment, Inclusion, Occupation and Identity) relate to the student's music therapy practice” some of the other questions that were asked of the data was "what can the data tell me about (need)" "What does (need) mean in my practice?" and "What is happening when (need) is identified?”. The fifth analysis phase was defining and naming the themes. As it was a framed by the deductive aspect of analysis, the main categories had already been supplied by 
Kitwood $(1997)^{8}$. However, within these categories the focus remained on the practice of the music therapist and using inductive analysis patterns of interventions started to become apparent within the data. During this final stage of analysis the main question that was asked was "what has the data shown me about this (need)". The results of these categories, themes and subthemes will be discussed in more detail during the Findings Section of this exegesis.

\section{Ethical Considerations}

Ethic approval for this study was granted by the Massey University Human Ethics Committee, Southern A Application 11/41. As this research was theoretically based and involved secondary analysis of clinical data the ethical risk was deemed low. However precautions were taken to ensure that due ethical considerations were followed. To fully address and understand the issues involved the therapist committed to ongoing scrutiny and careful reflection of any ethical risks by the research supervisor during the placement phase.

\section{Informed Consent}

Usual practice was not changed during the course of the research so it could not affect the practice or clients. This meant that during placement usual music therapy ethical guidelines for clinical practice was followed which included if necessary consulting the facility's Kaumātua ${ }^{9}$ and staff and engaging in on-going supervision for best practice.

An information sheet and ethics approval sheet was given to the facility manager and supervisor explaining the research and any supposed risks involved. Approval was given to go ahead with the research. Consultations with the facility liaisons and research supervisor confirmed that consent for individual involvement in the study was not deemed necessary apart from where a person’s data was directly used for illustration (i.e the vignette)

\footnotetext{
${ }^{8}$ Please see appendix for Kitwood's definitions of each need

${ }^{9}$ Kaumatua are Maori elders, in health care units they provide cultural advise for Pakeha (Europeans)
} 
The clients and guardians were approached for approval via the facility supervisor and information sheets and consent forms ${ }^{10}$ sent with contact information. As the client(s) had already left the facility there was deemed no ethical issues surrounding continued therapy. Any identifying features of both clients and staff and facility were removed during the secondary data analysis stage and kept on a password locked computer.

${ }^{10}$ Please see list of appendices for information and consent forms 


\section{FINDINGS}

The findings are presented under the headings Kitwood supplies in his model of needs.

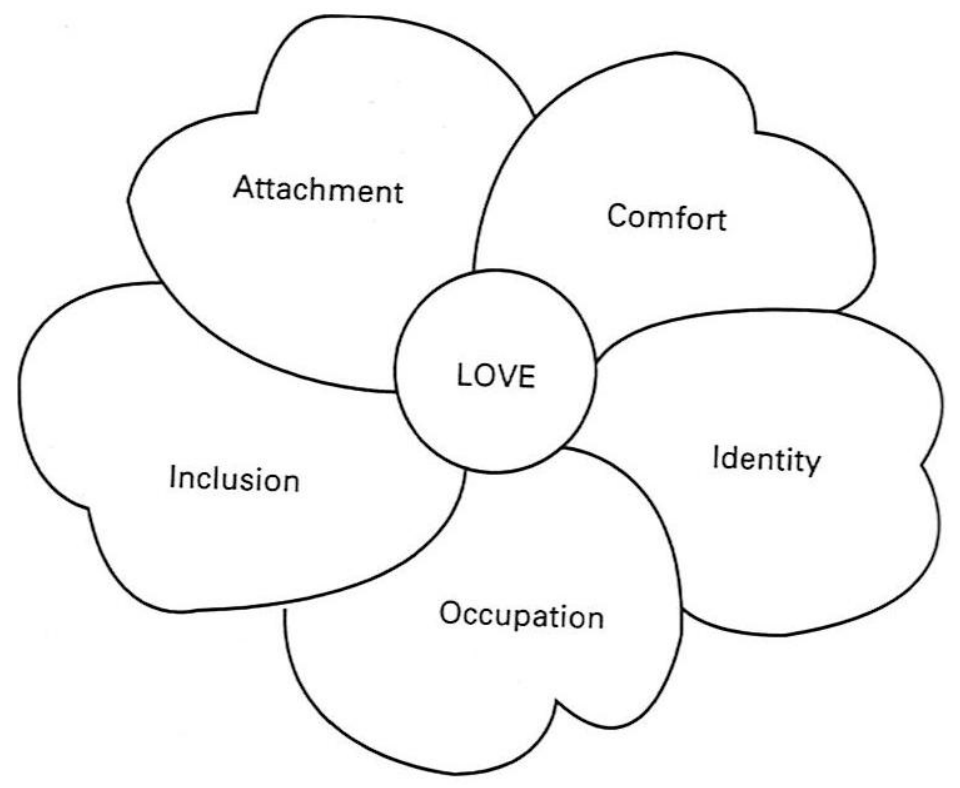

Figure 1: Kitwood’s five psychological needs. (1997, p.82)

The five needs in his model became the five categories in my deductive analysis. During my inductive stage and under these five categories/needs, themes and subthemes became apparent. These themes will be discussed in more detail under each category, describing the relationship that appeared to develop between them. Although clients' needs could be described as a subjective issue, overall themes in my findings can be validated by the use of the large sample size of clients and other research literature which will be discussed further in the discussion section. 


\section{Comfort}

"This word, in its original sense, carries meanings of tenderness, closeness, the soothing of pain and sorrow, the calming of anxiety, the feeling of security which comes from being close to another. To comfort another person is to provide a kind of warmth and strength which might enable them to remain in one piece when they are in danger of falling apart. In dementia the need for comfort is likely to be especially great when a person is dealing with a sense of loss, whether that arises from bereavement, the failing of abilities, or the ending of a long-established way of life. It has urgent moments, for example in times of parting, and it is also a continuing theme. The heightened sexual desire that is felt by some people with dementia may be interpreted, in part at least, as a manifestation of this need.” (Kitwood, 1997)

My findings will demonstrate there are several links between Kitwood's definition of comfort, what it means to need comfort and also what it means to provide comfort in my practice. Below are some of the main themes that the data has revealed on the need and use of comfort in practice.

\section{Comfort for client: theme one}

\section{Loss of usual lifestyle}

Summary of key subtheme relating to comfort and loss of usual lifestyle:

1) Loss of bonds of security:

- Familiar environment

- Someone close or familiar

- Physical closeness

- Physical movement

- Ability to communicate

\section{Explanation}

Loss of usual lifestyle appeared to be a large part of the need for comfort. These losses appeared compounded when a person was removed from their normal and structured environment. The loss of security, be it a familiar environment, person or abilities, appeared to affect the emotional and behavioural expression of the client. My data notes revealed that 
clients were often anxious and unsure of the new environment when arriving in the unit, taking several days to settle into the ward and to start to socialise with other people. This seemed amplified when there is a physical loss or loss of language ability. This made seeking comfort difficult, especially when usual relationships from a home environment were no longer present. Comfort appeared especially needed during this early period and again later, in times when clients (due to memory loss) became aware that this was not their usual environment again. I saw this when one client arrived on the ward. She had been there for two days but not ventured from her room. When I asked the lady how she was settling in she replied that "the nurses appear nice, but am unsure why or how long I'm going to be here for" (Clinical notes DP1, 2011, p. 8). This seemed to unsettle her, as I observed her face falling and becoming sad, meanwhile she began to wring her hands in an anxious manner.

\section{Providing comfort in practice}

\section{Intervention: theme one}

\section{3/4 Rhythmic music}

Summary of key subthemes relating to 3/4 music interventions and comfort:

1) Calms anxiety

2) Supports client's emotions to 'hold' them in one place

3) Rocking movement generated by the music appears to be self-soothing

\section{Explanation}

The key theme that kept showing up in the data when the need comfort was identified was the use of a 3/4 metre rhythm (a structured song or piece of music that uses three crotchet beats per bar). Although the melody or style of music was often different and suited to the individuals' preference, the use of $3 / 4$ music was identified at the core of the music intervention. 3/4 music appeared to be mainly used when clients became anxious. At first I 
used it intuitively, its purpose to partly to distract clients from anxious thoughts, but later I realised the rocking rhythm was something to 'hold' onto when uncertainties appeared strongly activated. It seemed that having a familiar song was a way of providing a familiar soundscape in an unfamiliar environment. The natural rocking movement that $3 / 4$ rhythm elicits in clients appeared linked to feelings or memories of being held and rocked and this seemed validated when I discovered Claire’s (2000) research ${ }^{11}$.

\section{Intervention: theme two}

Simple, quiet, gentle music or singing

Summary of key subthemes relating to above music intervention and comfort:

1) Can be relaxing

- Fills silence and gives space and time for a person to gather thoughts and respond

- Allows a person to reach a point where sleep is possible

2) Encourages expression

- Releases emotions

\section{Explanation}

I often used simple, soft and gentle music unconsciously and in informal settings. When I was sitting with a client, when they appeared upset, physically unwell or confined to bed, I would quietly sing or play improvised music based on their breathing, movement or verbal expression. On analysing the data I discovered that there were many examples when this style of music was used, and although often intuitively used, the results appeared to facilitate clients to relax into a state where they could either express how they were feeling, or allow them to rest or sleep.

${ }^{11}$ Please see discussion section 


\section{Intervention: theme three}

\section{Familiar music}

Summary of key subthemes relating to familiar music intervention and comfort:

1) Calls out to people "lost in the wilderness"

- Brings them back to the here and now

- Allows people to remain in one place

2) Reassures client of environment

3) Provides a feeling of security

\section{Explanation}

Familiar music was the use of music that was intrinsically linked to the identity of the client. I used cultural songs such Maori or Pacific Islander songs, religious songs such as 'Amazing Grace', early childhood songs such as 'She'll Be Coming Round the Mountain', or songs that held an important meaning in their lives (i.e. songs with name of client in it). Familiar songs were not just about reminiscing; they also provided a security for someone who had lost a familiar lifestyle; when a client recognised a song they were able to say, "I know this song. I found my way” (Clinical notes DP1, 2011, p. 14). Familiar music can be comforting because it can paint the new environment with the feeling of old familiarity, comforting and reassuring for the client. 


\begin{abstract}
Attachment
"Ours is a highly social species, and this is clearly shown in the forming of specific bongs or attachments. The pioneer of research in this field, John Bowlby (1979) claimed that bonding is a cross-cultural universal, and instinct-like in its nature. He suggested that it creates a kind of safety net, particularly in the first years of life, when the world is full of uncertainty. Without the reassurance that attachments provide it is difficult for any person, of whatever age, to function well. The loss of a primary attachment undermines the sense of security, and if several bonds are broken within a short time the effect can be devastating. There is every reason to suppose that the need for attachment remains when a person has dementia; indeed it may be as strong as in early childhood. Life is overshadowed by new uncertainties and anxieties, and some of the good memories from past secure attachments may be lost. Bere Miesen (1992), who has studied this topic in some detail, suggests that people with dementia are continually finding themselves in situations that they experience as 'strange', and that this powerfully activates the attachments need.” (Kitwood, 1997)
\end{abstract}

Attachment has many links to comfort; the idea of 'being there' and providing the bond of security needed by those who have lost several can easily be linked to feeling comforted. In attachment, there were some of the same losses as there were for the need comfort. However there appeared to be some subtle differences and below are some of the more detailed themes and subthemes that occurred when the need for attachment arose.

\title{
Attachment for client: theme one
}

Loss of relationships

Summary of key subthemes relating to loss of relationships and attachment:

1) Loss of relationship with family or loved ones

- Someone physically there in time and space

- Seeking sustained interaction

2) Loss of connection with society and life

- Depressed

- Feeling removed from society and living 


\section{Explanation}

A loss of a relationship appeared to be due to either an actual, physical or mental loss. During practice I saw clients with families or close friends visiting and/or with familiar photos but because of the loss of memory they had no connection to their previous attachment. "When S asked about the pictures on the wall and who they were $\mathrm{P}$ was able to answer who her son and sister were however could not name the people in other pictures and seemed distressed" (Clinical notes, DP1, 2011, pg. 8). There also appeared a loss of a connection or relationship with a client's life or society. This was mainly seen when I client remained by choice in their room, not wanting to interact with strangers or a lack of enthusiasm in previously favourite activities such as baking. Some of my clients also expressed thoughts of dying and depression.

\section{Attachment for client: theme two}

Loss of natural interaction

Summary of key subtheme relating to loss of natural interaction and attachment:

1) Needing a social or natural conversation/interaction.

- $\quad$ Need for someone to interact naturally - not in a role as carer.

\section{Explanation}

It was evident that many of my clients had a need for natural interaction in an ordinary and regular way. Sometimes when clients are in dementia care there is a lack of natural interaction. Often carers or families that are acting in the role of the main carers no longer have the time or understanding of their loved ones emotional needs to interact as they used to. This can be due the increased care required day to day, such as showering, and eating etc. It can also be due to lack of time or time spent in a more usual way such as sharing day to day stories. These environmental factors can greatly contribute to a loss of attachment. 


\section{Providing Attachment in practice}

\section{Intervention: theme one}

'Being there' in a moment in time: physically, musically and emotionally

Summary of key subtheme relating to 'being there' intervention and attachment in practice:

1) Allows client to be 'held', physically, musically and emotionally, acknowledging their worth.

- Verbal reassurance

- Using familiar music or clients name to provide security

\section{Explanation}

By being there physically, musically or emotionally I was hoping to allow a person to be secure in the knowledge that someone cared, reassuring them their worth. I used verbal reassurance when a client expressed a need for companionship "no one will talk to me" (Clinical notes DP1, 2011, p. 6). Usually this was supporting their feelings and reassuring them of their worth and where they were on the ward. Using familiar music or a client's name in music I found helped build rapport. It was a non-verbal way of saying "I understand who you are” and reflecting an understanding of what they were experiencing.

\section{Intervention: theme two}

'Free attention': Actively listening and responding, waiting, and allowing space in interaction

Summary of key subthemes relating to 'free attention' intervention and attachment in practice:

1) Fills need for sustained interaction

- Allows client to feel needed and supported

2) Reflecting emotions and behaviour through music

- Facilitates expression

- Encourages interaction and understanding 


\section{Explanation}

Being available for a client when they appeared anxious or upset or just listening was important to building trust and rapport. It also encouraged clients to discuss what was troubling them and provided opportunities for the therapist to direct conversations. This still allowed a client to feel heard, but gently moved them on to something that was less upsetting and less 'stuck'. It was important to take the time to be there and allow that client to feel more secure. This meant supporting the client in the most natural way possible. For example, being flexible, being there when needed, sitting quietly together, and sharing the same space. This theme was about being focused and 'in the moment' in the interaction, whenever an attachment need was present. 


\section{Inclusion}

"The social nature of human life has another aspect, related to the fact that we evolved as a species designed for life within face-to-face groups. To be part of the group was essential for survival, and in some cultures temporary exclusion was a form of severe punishment. The need for inclusion comes poignantly to the surface in dementia, perhaps in so-called attention-seeking behaviour, in tendencies to cling or hover, of in various forms of protest and disruption. In the ordinary settings of everyday life it is still very rare for people with mental impairments to be included with ease. Very often the social life of those who have dementia tends to dwindle away, as the dialectical interplay between neurological impairments and social psychology takes its course. In many old-style residential settings the need for inclusion was not addressed at all, as people were left together, but profoundly alone. Individualized care plans and packages, while a vast improvement, sometimes overlook this issue. If the need is not met a person is likely to decline and retreat, until life is lived almost entirely within the bubble of isolation that Tessa Perrin has described (p. 25) (sic.). When, however, the need is met, a person may be able to 'expand' again, recognized as having a distinct place in the shared life of a group.” (Kitwood, 1997)

There are many reasons why inclusion can be difficult for those living with dementia and mental health issues. The opposite of inclusion is isolation. Where isolation has been identified in the data, analysis has sought to see why and what might cause this to occur. While investigating this aspect in practice themes surrounding 'offering opportunities' occurred. Below are the themes and subthemes found under inclusion.

\section{Inclusion for client: theme one}

Loss of skills necessary to participate in usual activities

Summary of key subthemes relating to loss of skills and inclusion for client:

1) Loss of physical wellness

- Loss of movement: walking, standing, use of hands etc

- Too much movement: agitation, inability to stay still

2) Loss of mental wellness

- Paranoia

- Memory loss of familiar people 
- 'Attention seeking' behaviours ${ }^{12}$

\section{Explanation}

The loss of skills necessary to participate in a social setting can be the loss of physical or mental wellness, often there was a combination. However all of these inabilities resulted in a reduction in inclusion and ultimately isolation. The loss of physical wellness can be either loss of movement and bed isolation or too much movement as a result of agitation and need for occupation. The loss of mental wellness can bring with it signs of paranoia, being suspicious of motives and roles, loss of memory, inability to recognise people and therefore form relationships and be included with them. It can also include what nurses describe as 'attention seeking' behaviours, often expressions of "help me, help me” and “Can I sleep now?” (Clinical notes DP2, 2011, p. 21). These were sometimes repeated constantly due to short-term memory loss and an inability to remember what happened before. I believe these behaviours are expressions of need for inclusion as often they change as a result of thoughtful and planned music therapy intervention, involving steps that look at 'here and now' involvement.

\section{Providing Inclusion in Practice}

\section{Intervention: theme one}

Extending an offer of inclusion: providing opportunities for clients and staff to be included and interact

Summary of key subthemes relating to extending an offer of intervention and inclusion in practice:

1) Purposely using knowledge of clients or staff encourages inclusion

- Familiar songs can encourage participation and conversation about where and how they heard it and make a client feel included

- Playing requested songs make people feel important and acknowledges their role in the group

\footnotetext{
${ }^{12}$ This is an individual nurse's informal classification
} 
2) Semi-to-unstructured group sessions

- Encourages natural interaction: conversation, laughter

- Sharing of songs is linked to identities and sharing something about this knowledge with others

3) Modelling or directing appropriate interaction

- Verbally reassuring participants of role in activity puts people at ease, assuring them of their place in the group

- Filling gaps in conversation or activity keeps the flow in the session

- Playfulness and humour in interacting encourages natural interaction

- Staff to client inclusion removes barriers in care and creates natural interaction

\section{Explanation}

Purposefully using knowledge of staff and clients, such as using familiar songs and song requests in a semi-to-unstructured sessions allowed time and space to share stories and identities in a more natural way. Modelling appropriate social behaviour in groups allowed staff and clients to share more about who they are rather than what they do and boundaries and understanding appeared to increase. 


\section{Occupation}

"To be occupied means to be involved in the process of life in a way that is personally significant, and which draws on a person's abilities and powers. The opposite is a state of boredom, apathy and futility. The roots of occupation lie in infancy, as a child acquires the sense of agency: the realization that it is possible to evoke a response from others, and make things happen in the world. A person might be occupied in the company of others, or in solitude, in obvious action, in reflection or in relaxation. Often occupation involves having some kind of project, whether in work or leisure; it might, however, simply consist of play. If people are deprived of occupation their abilities begin to atrophy, and self-esteem drains away. The need for occupation is still present in dementia; it is clearly manifested, for example, when people want to help, or eagerly take part in activities and outings. It requires a great deal of skill and imagination to meet the need without imposing false solutions, crude and ready-made. The more that is known about a person's past, and particularly their deepest sources of satisfaction, the more likely it is that solutions will be found.” (1997)

There are many different types of occupation; there is reflection, relaxation, or obvious action. Kitwood describes it as being "involved in the process of life in a way that is personally significant” (1997). When someone is not able to be active in the process of life, self-esteem is stripped away; people can become isolated both physically and mentally. Below are the findings from the data analysis on what it might mean for clients with mental health issues to experience the loss of occupation.

\section{Occupation for client: theme one}

Loss of purpose in day to day living

Summary of key subthemes of loss of purpose in day to day living and occupation for clients:

1) Lack of personal achievements in day to day living - Loss of being able to show or share unique abilities or attributes

2) Boredom and apathy in ward - Lack of activities to suit level of ability

3) Loss of structure to time and day

- Dementia contributes to the loss of ability to sense time passing, making clients who live with it feel like it is never ending

- Continually searching for things 'I should be doing' 


\section{Explanation}

People who experienced a loss of purpose in day to day living demonstrated through one or several of the above categories. If a person was not able to share their unique abilities or attributes with others, apathy and boredom occurred. A lack of appropriate activities to suit both ability and attributes of clients produced the same effect. Personal observations made during this time appeared to show that with a lack of appropriate activities, time appeared never ending for some clients. This was later confirmed when one client commented, after a session had finished, that "when the music stops, everything seems to stop, people just go (hand gesture 'flat') and we are just waiting for it to start again” (Clinical notes DP3, 2011, p. 13). This suggests music brings people alive in the here and now, and that people with dementia may feel that they are actively participating in life.

\section{Providing Occupation in practice}

\section{Intervention: theme one}

\section{Familiar music}

Summary of key subthemes relating to familiar music intervention and occupation:

1) Using a clients favourite song

- Encourages engagement in group

- Re-engagement if they have left

- Staying for whole session

2) Can be stimulating

- Encourages active participation and movement

- Encourages physically moving in time to music/swaying, dancing, singing, or playing an instrument

\section{Explanation}

Familiar songs or identity songs that are important to the individual were often found in the data analysis. Individualising the music so that it involved the client in a personally important way was integral to my music therapy sessions. Furthermore clients were often stimulated to 
return to the session if that individual knowledge about their preferences was used (i.e. their playing a song, or starting up a conversation) to re-engage them in the moment. If they were new to the ward and there was no information about their history, songs from childhood, such as, 'She'll be coming round the mountain', or songs from their 20's would be used as a starting point to engage and help me learn more about their preferences.

\section{Intervention: theme two}

\section{Unfamiliar or improvised music}

Summary of key subthemes relating to unfamiliar or improvised music intervention and occupation:

1) Matching mood or behaviour of client

- Encourages engagement in group because it fills the need (agitation) that requires action

- Gives purpose to movements or vocalisations making action meaningful

- Singing or playing in time to clients walking help clients feel part of the music and activity

- Extending or repeating client's words in a song even if they are part of the dementia aphasia make it meaningful for the client so they don't feel frustrated or unheard

2) Gentle and reflective music to match client's mood

- Empathises with client feelings, acknowledging need to be occupied in reflection

3) Stimulating music

- Encourages clients to be active in the process of making up songs showcasing individual talent

- $\quad$ The process of improvising lyrics and music together increased clients socialising with others and a high level of playfulness

\section{Explanation}

Matching a client involved careful observation on part of the therapist. It involved carefully using what the client offered during the session to reflect it in back through the music. This made the interaction more meaningful. I had thought just familiar songs would be engaging and encourage interaction. However I discovered both familiar and unfamiliar music could have similar effects because to have either interaction effective the interaction must first 
match a client's emotion and need. Although it is certainly true that familiar music can have an immediate effect on a client, encouraging singing or playing of instruments, unfamiliar or improvised music can also occupy a person in the here and now by matching their emotions and reflecting their needs.

\section{Intervention: theme three}

Providing space in music and being open to impromptu activities

Summary of key subthemes relating to providing space and impromptu interventions and occupation:

1) Offers opportunities for people to showcase their individual skill or talent

- Space in the music allows for a client's 'special' ability to shine through

- Celebrates and acknowledges achievement or skill

- Allows a client a moment to be the centre of attention

2) Trying new songs can expand the therapists knowledge of the client

- Invokes new memories that can be shared

- Extends knowledge of client and links with Identity on 'holding' a identity that is slowly being lost

\section{Explanation}

Providing space and being flexible in sessions was important, being able to change with a client's needs at any time allowed (me the therapist) to follow the client and continue to support them in an activity. Taking risks in the music material was also important as I continued to be surprised by what clients knew and liked. Just assuming they only listened to, or enjoyed one type of music, (i.e. music from their 20's) could to a certain degree be misleading and would ultimately restricting their experience and personhood. In one session a client showed the outcome of providing these opportunities by coming around to the other end of the table and spontaneously asking for a dance, "We waltzed to two songs and his face seemed to light up with enjoyment.” (Clinical notes, DP3, 2011, p. 16). One client who was living with severe dementia and was often difficult to include due to his level of needs was able to be both engaged and included in the group by allowing space to contribute in a 
meaningful way: "N joined in by throwing his hands up in the air and saying "ta da!", it was a lovely way to finish and so nice to see him joining the group and in a non-confrontational and social way.” (Clinical notes, DP2, 2011, p. 13).

\section{Intervention: theme four}

Holding client in 'intent' of activity

Summary of key subthemes for holding 'intent' in intervention and occupation:

1) Having a plan, or structure for group

- Allows people to anticipant activities, keeping them engaged thinking ahead and more able to relax

2) Asking for requests engaged people in the here and now

- Keeps people active in the process of doing and living

- Keeps a person occupied in the moment allowing rest from confusing, agitating thoughts or behaviours

3) Verbally encouraging participation

- $\quad$ Reassured participant of skills, increased participation in singing and or playing instruments

\section{Explanation}

The intent of having an activity and knowing what was going to happen helped people be held in the moment and allowed them to relax making the intervention enjoyable and soothing. Asking for requests kept people active in the moment, encouraged focus of thought and rest from agitating thoughts and behaviours. With verbal encouragement people often opened up, talked about memories that had meaning in their lives, often referring it to current feelings or needs. Being occupied linked to bigger ideas of being part of something (the music, people), and having a purpose. My job was to give opportunities or purpose to day to day or moment to moment living, so that it was meaningful for the individual. 


\section{Identity}

"To have an identity is to know who one is, in cognition and in feeling. It means having a sense of continuity with the past; and hence a 'narrative', a story to present to others. It also involves creating some kind of consistency across the different roles and contexts of present life. To some extent identity is conferred by others, as they convey to a person subtle messages about his or her performance. How each individual constructs his or her identity is unique. In the 'old culture' of dementia care many of a person's sources of identity were taken away, particularly through the extremes of institutionalization and the removal of all contact with the past. We are learning now that much can be done to maintain identity in the face of cognitive impairment. Two things seem to be essential (Kitwood 1997a). The first is knowing in some detail about each individual's life history; even if a person cannot hold on to his or her own narrative identity, due to loss of memory, it can still be held by others. The second is empathy, through which it is possible to respond to a person as Thou, in the uniqueness of his or her being.” (Kitwood, 1997)

Identity is the unique attributes and personal experiences that make up an individual. It is why a person-centred approach to music therapy practice needs to be individualised. As dementia progresses, being able to remember or express the intricacies that make up a person's identity can become more difficult. Below are some of the ways identity loss appears to occur.

\section{Identity for client: theme one}

\section{Loss of memory and significant experiences}

Summary of key subthemes relating to loss of memory and identity for client:

1) Loss of recognising people who are close

- The confusion and frustration at not being able to name people

2) Loss of remembering significant parts of life

- Loss of memories of adulthood

- In advanced stages of dementia, the loss of memory can lead a client to believe they are younger than they are.

- $\quad$ Loss of memory can be upsetting when being (e.g. being told parents are no longer alive)

- Loss and frustration when not able to remember simple steps, i.e. how to use utensils, do up buttons etc 


\section{Explanation}

The loss of memory appeared to be very frightening when people with dementia had moments of awareness. There is a constant checking, “did we sing this song yesterday?” (Clinical notes DP2, 2011, p. 3). For other people the confusion is often made light of. However, for those patients experiencing advanced stages of dementia there appeared a link with childhood and an inability to remember that parents have already passed on that made reorientation unkind. Being constantly reminded that things are not as they were can make feelings of loss and grieving occur all over again.

\section{Identity for Client: theme two}

Loss of being able to verbally express identity

Summary of key subthemes relating to loss of verbal expression and identity:

1) Being unable to converse

- Can cause clients to withdraw and become more isolated

- When a client is unable to answer a question or respond appropriately frustration and agitation increases

- Talking about identity/history is harder than actively seeing or hearing identity cues

\section{Explanation}

Being unable to express an identity appeared to be a frustrating and an isolating experience. When a client tried to express an idea or memory and was unable to verbalise it, they often expressed their frustration through agitated behaviours, yelling or leaving the space. This contributed to isolation and a decrease in socialising. Clients often found expressing their identity easier when body language, pictures or music were used rather than verbal language. 


\section{Providing Identity in practice}

\section{Intervention: theme one}

Music extending knowledge and identity of client: Where no prior knowledge of client is known

Summary of key subthemes relating to extending knowledge intervention and identity in practice:

1) Good observation skill can provide clues for song choice and building rapport

- Song selection can be based on age, pictures or religious artefacts in room

- Culturally identifying features such as an accent or surname can be used to build rapport and sharing of identities

- If correctly guessed, client may elaborate on song and subject, offering a snowball effect

\section{Explanation}

Extending knowledge of clients who are either unable to verbally communicate their history or unable to remember it can sometimes be a guessing game. The data revealed that having good observation skills improved the therapist's ability to extend a client's identity. Being sensitive to small details and using them to gently prompt a person can have a significant effect in reminding people of their experiences and identity in society.

\section{Intervention: theme two}

\section{Extending and holding identities}

Summary of key subthemes relating to extending and holding interventions and identity in practice:

1) Song choice is used to extend knowledge of client

- A continued sense of self and identity is extended when knowledge of client's identity is used to engage client in music or activity

2) Familiar songs can hold an identity for a client

- Songs that call forth memories can be used to 'hold' a person's identity when they are unable to remember themselves.

- Use of a name in song can often remind, reassure and comfort clients who experience the confusion that memory loss brings

3) Active listening extends knowledge of client 
- Asking questions and being interested encourages clients to elaborate

- Providing space in the music and conversation gives client's time to think about experiences

- Asking for requests of songs

\section{Explanation}

Song choice was used to draw out and extend the therapist's knowledge of a person's identity. The more that was known about a person's identity the more the music therapist was able to engage the client and build rapport. There was also a musical aspect of it 'holding' a person's identity like a song tag. Songs were often linked to certain memories and emotions. By playing a specific song a person may again be able to experience the security and knowledge that 'knowing who you are' brings. Actively listening and responding was about being in the moment with the person, following not just their words but also their body language. When this was done the music therapist was able to respond more holistically to their needs. The data revealed that often conversations were more coherent and clients were more socially active after conversations or when music from a person's history had been shared.

\section{Summary}

Kitwood's model of needs was helpful to me in understanding the behaviours and interactions of people living with dementia. For some people these behaviours were an outlet for what they appeared to be experiencing and for others it appeared to come from a need to be understood. My music therapy practice and person-centred approach sought to provide some of the basic needs Kitwood describes in his model. Like Kitwood's model of needs the therapy overlapped, where familiar music provided both comfort and attachment often addressing different needs simultaneously. Below is an example of how these needs manifested for a woman who was both physically and mentally isolated and how music therapy practice was used meet them. 


\section{Case Vignette}

\section{Background}

I met Joy (pseudonym) on her second admission to the unit. She had been on the ward for a few months before I got a referral from a nurse for music therapy. I was told she had had an early onset of dementia, and was now living with an advanced stage even though she was in her late 60's. From her notes I found out that Joy was visually impaired, but that doctors were not sure to what degree, due to her inability to respond verbally. I had observed, previous to working with her, that she spent a lot of time by herself in her room and that during assisted walks around the ward she would race, pull the carer along behind her, and at times yell loudly and swear, upsetting some of the other patients. Joy had developed what appeared to be 'expressive aphasia', which is commonly described as word-salad, where the correct intonation for conversation is used but not the correct words. In her notes I saw that someone from the medical team had written that Joy's goals were focused on building rapport and interaction. Her ability in both of these areas had decreased over time with her advancement of dementia and care notes were focused on maintaining them. I had only been on placement one month at the unit before working with Joy and was somewhat nervous because although she was physically very active, as a client she was also the most severely affected patient I had worked with before. A few sessions in I also found out that I needed to be careful as there had been a few incidents with nurses being hurt by Joy. I spent 12 sessions working with Joy over a total of two months.

\section{Beginnings}

$4^{\text {th }}$ of May 2011 (Wednesday)

\section{Individual session with Joy in her room: first assessment}

2:15 to $3: 00$

My first session with Joy was to assess her needs and see how I might help reduce some of her obvious agitation. When I entered her room I saw a small and slight woman with untidy grey hair sitting, chewing her nails, and talking to herself. I introduced myself gently, saying I was a student music therapist and that a nurse had 
thought she might like some music, but that I could leave whenever she wanted. I started with 'I had a dream' by ABBA as the nurse had told me that ABBA and Boney $M$ were Joy's favourite bands as well as the classic songs such as 'You are my sunshine'. I noticed little reaction to the music and Joy continued walking around the room talking constantly and touching objects such as the bed and bathroom taps in her small room. I realised that music that reflected her movements would perhaps be a more appropriate place to start. I improvised a rhythm to her walking and incorporating some of her words hoping to build a more non-verbal connection. Pausing between her vocalisations I noticed a sort of natural conversational rhythm. When I extended them with the guitar she seemed to slowly become more aware of my presence. Joy appeared to settle and she eventually sat down and sighed. She looked up at me, and when she started talking it felt as if she was talking directly to me. She even paused to allow me space to comment before talking again. Slowly I picked up on a word she had said, and we started talking about cows and farms. This seemed to help validate and give purpose to her conversation and she slowed her talking down and appeared calmer. I wondered if it was perhaps because Joy was feeling heard or more understood by me, or maybe she just became used to my presence in the room.

$9^{\text {th }}$ of May 2011 (Monday)

\section{Individual session with Joy in her room: second assessment}

10:45 to $11: 30$

Joy was sitting quietly drinking when I arrived; she was also chewing her nails. I sat down on her bed opposite and started playing quietly. I started with 'I had a dream' from ABBA again. Joy was staring into space, but seemed to be tapping her foot in time with music this time. Joy sat quietly for a long period while I played 'Fernando', 'You are my sunshine' and 'yellow taxi'. I felt some songs definitely had more meaning for Joy. She sighed, smiled and during 'Fernando' she looked towards me, made eye contact and joined me in nodding and swaying in time to the song. This felt significant, it felt like we had finally found a way to communicate and were just starting to learn about each other. Joy started chewing her nails again but at the same time moved from her chair to sit on the bed with me. When I saw Joy sigh heavily and say she was 'sore' I changed the rhythm to a slower pace and started improvising on E minor and A major pivot incorporating Joy's name. Joy started 
saying "I love you, yes I do; you are a sweetie" and I thought that part of this may have been her need for self soothing, and that she was seeking comfort and attachment. The music appeared to hold and sooth Joy while also allowing space for her to express herself. I finished with the classic 'Now is the Hour' and Joy surprised me by, for the first time, singing along with some of the words. I left quietly not long after.

\section{Building a relationship}

Summary of Sessions: $11^{\text {th }}$ of May 2011 to $15^{\text {th }}$ of June 2011

In the following five sessions after the initial assessment period Joy and I continued to build understanding in our relationship. Learning boundaries (when to stay, when to stop, physical touch etc) and the importance of space and sharing identities was my focus. Joy started actually singing along to most of the words in familiar songs and if she lost them would hum along. Each session was unique and I approached it with a flexibility that allowed me to join Joy with warmth and humanity. I found out that when Joy was unwell she could experience hallucinations, once talking to a "dog", and at times saying she was "sore", sighing and saying "I'm not well; I've got a sore tummy”. I found that I improvised more during these sessions, focusing on calming, repetitive chords to try and bring her agitated mood down to a more comfortable one.

There were many joyful moments too. There was one session where Joy appeared especially active and present in the here and now. She was busy walking around the room, leaving and then coming back to me, putting her arm around me and kissing my forehead several times and saying "you're beautiful, beautiful my darling”. I noted that although Joy was more active in walking there was a difference to the pressured agitated state in which she usually walked, and that this felt more like excitement than agitation. I hugged Joy back warmly, knowing that on one level her need for touch may be related to sensory failings, while on the other deeply feeling her need for comfort may come from a special attachment that has grown over time between us.

We also shared moments that were intrinsically sad. One such moment was the second time I played her 'You are my sunshine'; Joy sang and hummed along with some of the words, but towards the end of the song her expression became teary and very clearly said "mum". I gently asked what it meant for her when we finished the 
song and she paused, kissed my head and said "it's special". This is the clearest and most moving moment I have had with Joy. The music seemed to bring her to a quieter calmer space where she was able to express herself. I felt that being able to express these needs and working through them rather than dismissing them was an important aspect in the therapy for Joy.

\section{The journey to wellness}

Summary of sessions: $29^{\text {th }}$ of June 2011 to $18^{\text {th }}$ of July 2011

After these sessions Joy seemed more aware, verbal and active. She was talking a lot more and I felt that we had built a relationship where she knew she could communicate with me without the need for words. In the past, a non-verbal calm space needed to be created before Joy was able to focus and express herself. However, in one later session Joy was already waiting and ready when I arrived. I finally realised this when she said "be quiet!" and started talking about something (selling a car?) which seemed to worry her. The conversations seemed to become more coherent with not just words but also sentences that made sense. She was clearly able to tell me "I'm unwell today" and wanted "Her Johnny" (pseudonym for husband) saying she loved him "so much". She seemed tired and teary that day so I suggested that we could sing a song for him. I improvised a 3/4 DGAD chord progression with a rocking rhythm to help comfort and soothe. Joy put her arm over my shoulder and we rocked together in time to the music. I later played 'Fernando' saying she might remember or know this song. There appeared to be real joy in her face as we sang the chorus, a smiling from her soul and identity. Towards the end she seemed to become very aware saying "There is something wrong with me....I don't know this song??" I reassured her saying yes she did remember it, she had been singing beautifully, and this seemed to ease her confused state and put her at peace. I realised that more than just the dementia, Joy has also been struggling with the depression that follows the moments of clarity and awareness of something wrong. I realised that her needs for comfort, and the security that comes with attachment, shaped the road for wellness for Joy. By my being open and flexible in sessions Joy could express herself and allow these needs to be filled. 


\section{Farewells}

$20^{\text {th }}$ of July 2011 (Wednesday)

$1: 10$ to $1: 40$

Discharge in the facility can change from hour to hour, day to day, so I had little warning of Joy being discharged from the ward. In what turned out to be our final session, Joy greeted me warmly and with a hug. I improvised around familiar songs and chords, at one point putting down my guitar to dance a few steps with her. There literally seemed to be more 'joy' in her today although there were still some sad or perhaps frustrated moments which I reflected in the improvisations (Em Am7). Joy appeared centred, still, and calmly sat and listened, sometimes interjecting verbally through the improvisation. When the music reached Joy, it felt as if we were connecting as equals through the music, meeting eye to eye and the disease was stripped away. This is the memory I carry with me. People living with dementia are not shadows; they are still living here and now. It is important that they are given the opportunity to express their needs and feel acknowledged as the unique individuals they are. 


\section{DISCUSSION}

Joy's story reinforced to me how each case of dementia and mental health is different, reflecting the differences in need and unique identity of the client. Kitwood's holistic model of needs looks specifically at the basic needs each person requires. Without these needs being met “a human being cannot function, even minimally, as a person” (Kitwood, 1997, p. 81). They are complex, overlap in areas and can be difficult to define. However the ultimate focus of Kitwood's model of needs was providing individual care in a holistic manner. My music therapy practice likewise focuses on client's needs and meeting them through a selection of interventions. I found these were: resonating with the emotions of a client, seeing a need and responding thoughtfully; 'being there' for a client, physically, musically and mentally; offering opportunities, being flexible and adjusting to a client's ability; giving purpose to movement and allowing space for a client to be a part of something; and by holding and extending identity by making astute choices of music to increase knowledge of the client.

In my data analysis of comfort, attachment, inclusion, occupation and identity I found that there were several different types of loss of basic needs which contributed to behaviours. Analysis of music therapy practice showed several mixed interventions were used to meet these needs. The following sections will discuss in further detail each category/need and how they related to Kitwood and other research.

\section{Comfort}

In my findings, the specific need for comfort was demonstrated by patients due to loss of lifestyle, environment, people or familiar bonds of security. These losses could occur at different times for patients but usually it was compounded when they experienced a new and unfamiliar environment or people. The experience of entering into a new and unfamiliar environment where no-one is familiar and usual routines were disrupted or removed could be 
a frightening experience, even for those who might be well. Kitwood (1997) also describes the need for comfort occurring in times of loss "whether that arises from bereavement, the failing of abilities, or the ending of a long-established way of life” (p. 82). When these securities are lost there is a tendency to remain in one place, isolated, usually for long periods of the day.

In the loss of physical comfort, Kitwood talked about "The heightened sexual desire that is felt by some people with dementia” (1997). In many cases I found this need could be understood in its most basic form, the need for physical contact and comfort. Although this may be a simplistic view I found that holding a hand, an arm on a shoulder, or sitting close by could fill this need for comfort, and was often expressed by the client to me in the same way. Brotons wrote about the need for touch in late stage dementia in her chapter on 'An Overview of the Music Therapy Literature Relating to Elderly People' (Brotons, 2000). She found that patients showed a greater response in participation and social behaviours when touch was initiated during music therapy rhythm exercises.

An example from the data source on touch and comfort revealed some interesting links with Kitwood's other needs: “G tapped me several times on the shoulder and seemed to want to engage although he didn’t sit down. I sang him ‘Oh Danny Boy’ changing the lyrics to 'oh G boy' to engage him appropriately in music” (Clinical notes DP2, 2011, p. 2). This showed me that comfort was closely linked to attachment and inclusion. When someone was comforted they appeared to become more secure in a relationship. This can be seen as building rapport or trust with someone and this trusting relationship can then be used to encourage the client's inclusion in group.

Bland, a New Zealand professor in nursing, looked at the idea of comfort in nursing care (Bland, 2006). She found that comfort was more than just the absence of discomfort but that 
it was dynamic in nature and context dependent. Like Kitwood, she expresses the need for individualised care based on the needs and preferences of residents. Individualised music interventions have been shown to have greater affect in reducing agitation (Gerdner, 2005). Ruth Remington (2002) found that both individualised and familiar music has an effect on reducing physical agitation, pain control and verbal agitation. Familiar music is linked to all of Kitwood's needs in his model and appears to be a technique often used by other practitioners in these settings (Clair, 2000; Gerdner, 2005; Remington, 2002; Tomaino, 1999). I found that familiar music was not just about reminiscing. Familiar music was found to be comforting because it provided security and reassurance. One client said after a familiar song that "I found my way” (Clinical notes DP1, p. 14), suggesting music calls out to people, drawing them into the here and now and away from the continuous and often upsetting confused thoughts.

In Brotons' review of the music therapy literature for elderly people she found several studies linked sleep facilitation and music, with patients who displayed ADRD (2000). This supports my findings that familiar, simple and 3/4 rhythmic music helps clients who needed comfort. For example, music soothed anxieties', encouraged expression and allowed for relaxation in times of agitation. Clair (2000) rationalises this style of music by saying "singing connects with, or results from, individuals' experiences in which they were held, rocked, patted and sung to when they were in need of comfort” (p.83). Moreover when Simpson (2000) talked about comfort he felt that music was an important aspect because it reached depths of the consciousness that "far surpass the level that can be reached by words" (p.182) supporting the unique limitations people living with dementia and mental health issues face. This appears to support a link between Kitwood's idea of comfort and a music therapy practice. 


\section{Attachment}

I found that it was a loss of relationship and natural interactions which brought forth the need for attachment in practice. Aldridge (2000) found similar connections between relationship loss and communication difficulties, saying "when communication fails, we literally 'fall out' with other people, we fall out of relationship” and goes on to say that this causes people to "fail to connect to the rhythms of daily life, to other people and within themselves" (p. 16). Kitwood (1997) also talks about how the loss of memories from past secure attachments can affect people living with dementia. He writes that a loss of several bonds of attachment may start to overshadowed life with "new uncertainties and anxieties" (p. 82), and that ultimately it can be a barrier to allowing a person to function well ${ }^{13}$.

In practice there were several different interventions simultaneously used to meet the need for attachment. There was an overarching theme of 'being there' for the client which seemed to be the basic premise for providing attachment. Then under this overarching theme there were several subthemes and categories. Many of the methods used in the interventions were ones that could be found in a natural friendship, like physically being there for a person, and providing free attention by listening and responding to concerns and emotions.

In music interventions I discovered that matching music to a client's behaviour provided a non-verbal way of connecting and showing an understanding of a client's need. Clair (2000) suggests this is because non-verbal expressions of emotions are "important to the initial awareness of feelings” (p. 86). Aldridge (2000) elaborates on this to suggest that it is music which forms the basis of relationships and that it is through the use of rhythm and timbre people may form connections. In using familiar music a music therapist can acknowledge someone's worth in a relationship, show that he or she knows and cares about the individual

\footnotetext{
${ }^{13}$ Please see Bowlby's (1988) attachment theory which Kitwood draws his theoretical and psychoanalytical perspectives from.
} 
and ultimately builds rapport and trust. The same can be achieved by using a client's name in a song. Meeting the need of Attachment was about using all the therapeutic techniques a music therapist brings to a session; physicality, verbal reassurance, and musical elements.

\section{Inclusion}

I found it was a loss of skills necessary to participate in usual activities that caused a lack of inclusion. This was seen when someone was physically or mentally unwell or a combination of both. A usual understanding of someone being physically unwell is when a person is unable to operate parts of their body; this could be muscle movement such as walking, or use of hands etc. The other aspect of physical un-wellness is when someone is unable to control muscle movement, and demonstrates agitation and the lack of ability to stay still. Physical unwellness in clients can lead to isolation and effect exclusion from groups. When someone is mentally unwell they could be suffering from psychosis, paranoia, and display attention seeking behaviours because of loss of memory or time-space continuum. Vicky Abad, a music therapist, wrote an article about her client “John” and how both his memory loss and physical inability to leave his room due to obesity contributed to him becoming isolated and aggressive to attempts to socialise with him (2001). She recommends music therapy as an intervention for inclusion, quoting Clair and Bernstein’s (1990) research which found that "music may be one of the only media through which social interaction with others occurs in meaningful ways for people with dementia” (Abad, 2001, p. 2).

I found that in practice extending an offer for clients who are physically and/or mentally isolated was one of the first steps in making someone feel included. I found that by purposely using individual knowledge about a client or staff, having semi-structured group sessions, and by modelling or directing appropriate interaction thoughtfully, a person could be encouraged to join in and feel included. Using familiar songs was a way of using knowledge of a client's 
identity to encourage feelings of inclusion. Familiar songs helped draw clients in, making them feel known and part of the session. This was helpful even when clients were unable to sit down due to agitation. By using a special familiar song a client could continue to feel included from afar. Abad's (2001) found similar results on inclusion and music therapy in her own practice as did Pollock \& Nomzi’s (1992) and Sambanham \& Schim’s (1995) research where subjects had an increased social interaction after individualised music therapy sessions.

Staff in the ward where the current study was based often requested music therapy when a client was unwell or isolated and they felt they were unable to be included in other ways. Music therapy was one activity which was able to successfully cater to a wide range of needs, allowing everyone, regardless of physical or mental un-wellness to participate. Abad's (2000) research on inclusion reflected the value of music therapy in this field by providing quantitative statistics of two three month periods which showed "consistently higher attendance in music therapy” (p. 4), despite the inevitable progression of dementia.

\section{Occupation}

I found the need for occupation was reflected as a loss of purpose in day to day living. This could be a lack of personal achievements, boredom and apathy or a loss of structure to time and day. Kitwood describes occupation as being "involved in the process of life in a way that is personally significant, and which draws on a person's abilities and powers” and that with a loss of occupation, self-esteem would drain away (Kitwood, 1997). Other authors have described the importance of individualised intervention so that people who have lost the ability to create meaningful activity are comfortable and an experience of success is always achieved (Abad, 2001; Gardiner, Furois, Tansley, \& Morgan, 2000; Svansdottir \& Snaedal, 2006). 
Occupation is not just actively participating. There is also passive occupation where someone can be occupied in reflection or relaxation. Music therapy has the ability to meet the level of occupation a client needs. This can be using more familiar music and allowing clients to sit and listen, gently sing along to certain songs or actively dance, play instruments, whistle, and laugh and engage in the music. Svansdottir and Snaedal (2006) found music allowed every patient to participate actively or passively, making it possible to include patients with different stages of dementia in the same sessions.

The use of unfamiliar or improvised music can provide freedom for both the therapist and clients. It can be used to give meaning to action, help people feel part of the music so they can feel heard and understood. Matching clients in music can be especially useful when a person is living in the later stages of dementia. Being active in music therapy sessions could provide meaning to people who have lost the capacity to create meaningful activity for themselves (Svansdottir \& Snaedal, 2006). With the loss of verbal communication, agitation within this context is often thought of as an expression for communication rather than symptom of the disease. The data showed me that giving purpose to verbal outbursts or agitated movements can be helpful in acknowledging a clients need for expression and participation.

In communication studies, it has been suggested that the body aspect has been somewhat neglected (Aldridge, 2000). Yet it is gesture that is pre-verbal and promotes cognition, and as Aldridge points out "the body, and a moved body at that, is central to a life” (Aldridge, 2000, p. 13). Movement is useful in stimulating thought, engaging people in the process of here and now living and encouraging playfulness in sharing and interacting with others. Nugent (2003) suggests that matching the music to the mood and participation level of the group to increases cohesion and active methods such as movement and instrumental playing as they can often channel psychomotor agitation in a more meaningful way. 
Tomaino (1999) also found that "interesting rhythmic patterns and novel or familiar music may increase both attention and motivation" (p. 118) encouraging both engagement in activity, engagement from afar, or re-engaging a client after leaving the music therapy group. This reinforces my findings on the need for occupation.

Another aspect of occupation in practice was the use of providing space and being open to impromptu requests for engagement. Although a simple thought, this proved a powerful method in supporting a client's need for having purpose and an outlet for meaningful expression. Trying new songs was a way to continue occupation so clients did not become bored with material but also because it often offered new memories and stories contributing to the need identity. Offering space for people to showcase individual skills and talent was essential in them having agency in life. It is "the disability to perform our life's story further" which leads to distress and apathy (Aldridge, 2000, p. 20).

In closing it is important to remember how difficult it can be to elicit any behaviour from people living with dementia, much less to observe spontaneous positive interaction with other people. Brotons (2000) found that music therapy can foster and enhance social behaviours, decrease agitation and access cogitative skills among clients (p. 54).

\section{Identity}

I have found that a loss of memory and opportunities to remember or express identity contributed to a loss of personhood and identity. Aldridge (2000) claims that "our perception of self is dependent upon coherence in time” (p. 17). With the loss of memory structuring the events in time, people are unable to have a narrative or identity for self. However, Aldridge argues that temporal coherence can be replaced by a musical form because it offers an external sense of time and space. Having a sense of identity is essential to having continuity with the past and having a narrative and a story to present to others (Aldridge, 2000; 
Kitwood, 1997). Narratives are constructed and interpreted; they lend meaning to what happens in daily life and can be used to maintain personhood in the face of failing mental powers (Aldridge, 2000; Kitwood, 1997).

Music therapy was used to hold and extend a client's identity. This required good observation skills to identify significant features of client, making astute song choices, and active listening and responding. Cultural identifiers such as knowledge of a client's iwi ${ }^{14}$ or place of birth provided a point of reference for beginning sessions with new clients especially with those unable to verbally communicate. These familiar songs had the ability to call forth memories, provide comfort and security in the personal knowledge that 'I know this song; therefore I know who I am. Tomaino (1999) talks about this same idea by stating that "familiar songs become a tool for connecting to seemingly lost parts of the personality by providing a necessary link to the "self"” (p. 116). She writes that rich association keeps melodies alive throughout people's lives, and that memories are not actually lost with dementia or other brain injuries, but that it is the ability to retrieve and access them that is damaged. She elaborates that "music, then, can provide access not only to specific moods and memories, but also to the entire thought-structure and personality of the past." (p. 117).

Providing space and opportunities for people to express and extend their knowledge of their own identity was also an important but subtle detail in my findings. Often I was provided this need unconsciously but just sitting with someone and listening. This closely links to the need for occupation. Aldridge (2000) writes that "we perform our very selves in the world as activities” (p. 14) as this underlies the concept that we 'do' who we are. People tell us their stories expecting to be heard, they have a structure and context connected with the fabric of communication, rather like music has a structure and dynamics of expression (Aldridge, 2000). Therefore through providing activities such as music therapy, which links not only

\footnotetext{
${ }^{14}$ Maori tribe
} 
with memory retrieval but non-verbal expression, we are able to provide active opportunities to maintain identity through an individualised performance of self.

\section{Limitations}

There were a few limitations to this study. One was the lack of detail in Kitwood's definition of needs. This is why although love was an overriding theme in Kitwood's model of needs it was not incorporated into the investigation of music therapy practice. Kitwood does provide an outline of the five needs ${ }^{15}$ but fails to provide more detail, I believe, because of the complex and individualised understanding of these needs. This made it quite difficult to provide really consistent coding (I was aware that there was probably some variability between clients in how I coded the data during the analysis stage) and other researchers may perhaps find different links.

Another limitation for the study may also have been the secondary analysis, limiting research questions and methods and methodology in uncovering aspects of research. However, in this stage of my learning the focus was on my practice and learning research processes, so secondary analysis was appropriate in allowing this learning to take place, but perhaps limited the ways in which to do it.

There were many aspects of my practice that I wished to understand in more detail; for instance the inclusion of staff in sessions and how this affected changes in care or understanding. In addition it would have been insightful perhaps to have included or understood more about the individual and complex medical and mental health issues people had on the ward. However due to the size of the research question this made it inadvisable to elaborate on staff interaction and other mental health symptoms, such as depression, psychosis, and delusions etc. However, in future it would be interesting to investigate the

${ }^{15}$ Please see list of appendices 
impact of a music therapy practice arriving on the ward and the influences it had on staff in regards to levels of care, changes to client behaviour and perceptions of a music therapy practice in that setting. 


\section{CONCLUSION}

Kitwood's (1997) book, 'Dementia Reconsidered' brought person-centred care to the forefront of dementia research. Nursing literature and practice continues to use his personhood theory as it allows those present to see the person in the context of their past rather than the context of the disease, ultimately improving levels of care (Wills \& Day, 2008). They also found that this also reduced agitation and improved quality of life (Chenoweth, et al., 2009; Wall \& Duffy, 2010). Allied health professionals such as music therapists have also found Kitwood's model of needs to be meaningful. Simpson (2000) found that it helped him understand his practice and the "vital essence of personhood" (p. 182) that remains intact even for people with advanced dementia. While Ridder and Aldridge (2005) found that it helped them understand links between meeting psychosocial needs and the different stages involved in music therapy sessions.

Kitwood's personhood theory encourages everyone to look at people living with dementia as unique individuals. He stresses the need for individual care regardless of their stage of dementia. His model of needs investigates the basic needs people who have dementia require to have wellness in their lives (Kitwood, 1997). He suggested that dementia progresses not just biologically but also due to factors such as environment. Therefore a change in the environment such as in intervention could affect the progression of dementia. Based on Kitwood's reasoning, I looked back on my practice to find if there was any relationship between interventions in practice and meeting clients needs. Using his five needs I sought to understand people living with dementia. It gave me more understanding of their behaviours and needs in society. My findings, along with evidence from other researchers, suggest a positive relationship between music therapy and Kitwood's model that supports the use of music therapy in both dementia and mental health settings (Abad, 2001; Aldridge, 2000; Dewing, 2008; Nugent, 2003; NZMOH, 2002; Powell, 2006; Ridder \& Aldridge, 2005; 
Ridder, 2011; Sherratt, Thornton, \& Hatton, 2003; Sherratt, et al., 2004; Simpson, 2000; Wall \& Duffy, 2010).

My findings revealed that careful interventions allowed clients to participate more fully in the process of life. This was achieved by reducing agitation by providing comfort, building new attachments and securities through natural interaction and free attention, providing activities that encouraged here and now and time-coherence structuring, offering opportunities that provided appropriate modelling for interacting socially, and by holding and extending identities through music reminiscing. As demonstrated in my vignette, music therapy was a holistic approach, providing opportunities for self-expression and differing needs as they arose during the sessions.

Music therapy in this setting is not an end point of care as there is no current cure for dementia. However, music therapy is there to assist people living with this debilitating syndrome through the meeting of basic and fundamental needs that everyone, regardless of disease, requires to function well (Kitwood, 1997). As Kotai-Ewers (2000) suggests "To be heard and accepted as a worthwhile and unique human being is what we all seek in life” (p. 79). My music therapy practice was about offering a space and chance for the clients to experience, enjoy, take an active part in life, share with others who they were, what they had to offer and celebrate their unique identity of self. Person-centred care is about all of these things and music therapy practice offers the holistic approach that Kitwood's (1997) model of needs advocates. 


\section{REFERENCES}

Abad, V. (2001). Reaching the Socially Isolated Person with Alzheimer's Disease Through Group Music Therapy - A Case Report. [Case Study]. Voices: A World Forum for Music Therapy, 2(3), 6.

Aldridge, D. (2000). Overture: It's not what you do but the way that you do it. In D. Aldridge (Ed.), Music Therapy in Dementia Care. London: Jessica Kingsley Publishers.

Bartlett, R., \& O'Connor, D. (2010). Broadening the dementia debate: towards social citizenship. Bristol: Policy Press.

Bland, M. (2006). Betwixt and between: a critical ethnography of comfort in New Zealand residential aged care. [Older People]. Clinical Nursing, 16(937-944), 7.

Bowlby, R. J. M. (1988). A secure base: clinical applications of attachment theory. Oxon \& New York: Routelge.

Braun, V., \& Clarke, V. (2006). Using thematic analysis in psychology. Qualitative Research in Psychology, 3((2)), 77 - 101.

Brotons, M., . (2000). An Overview of the Music Therapy Literature Relating to Elderly People. In D. Aldridge (Ed.), Music Therapy in Dementia Care. London: Jessica Kingsley Publishers Ltd.

Bruscia, K. E. (2005a). Designing Qualitative Research. In B. L. Wheeler (Ed.), Music Therapy Research (Second Edition ed.). Gilsum: Barcelona Publishers.

Bruscia, K. E. (2005b). Developing Theory. In B. L. Wheeler (Ed.), Music Therapy Research (2nd ed.). Gilsum: Barcelona Publishers.

Chenoweth, L., King, M. T., Jean, Y.-H., Brodaty, H., Stein-Parbury, J., Norman, R., et al. (2009). Caring for Aged Dementia Care Resident Study (CADRES) of person-centred care, dementia-care mapping, and usual care in dementia: a cluster-randomised trial. 8(April).

Clair, A. A. (2000). The Importance of Singing with Elderly Patients. In D. Aldridge (Ed.), Music Therapy in Dementia Care. London: Jessica Kingsley Publishers.

Dewing, J. (2008). Personhood and dementia: revisiting Tom Kitwood's ideas. International Journal of Older People Nursing, 3, 3-13.

Epstein, I. (2010). Clinical Data-Mining, Intergrating Practice and Research. In T. Tripodi (Ed.), Pocket Guides to Social Worck Resarch Methods. Ohio: Oxford University Press.

Gardiner, J. C., Furois, M., Tansley, D. P., \& Morgan, B. (2000). Music Therapy and Reading as Intervention Strategies for Disruptive Behavior in Dementia. Clinical Gerontologist, 22(1), 31 - 46. 
Gerdner, L. A. (2005). Use of individualized music by trained staff and family: translating research into practice. Journal of Gerontological Nursing, 31(6), 22-30; quiz 55-56.

Goodall, D., \& Etters, L. (2005). The Therapeutic Use of Music on Agitated Behavior in Those With Dementia. Holistic nursing practice., 19(6), 258-262.

Kitwood, T. (1997). Dementia Reconsidered, the person comes first (2nd ed.). Buckingham: Open University Press.

Kotai-Ewers, T. (2000). Working with Words, People with Dementia and the Significance of Narratives. In D. Aldridge (Ed.), Music Therapy in Dementia Care, More New Voices (pp. 63 to 80). London and Philadelphia: Jessica Kingsley Publishers.

Laugesen, R. (2011). 'Good morning sweetheart'. Listener, April 16.

Munk-Madsen, N. M. (2001). Assessment in Music Therapy with Clients Suffering from Dementia. Nordic Journal of Music Therapy, 10(2), 205 - 208.

Nugent, N. (2003). Processes in Group Music Therapy: Reducing Agitation in Individuals with Alzheimer's Disease and Related Disorders (ADRD's). Paper presented at the NZSMT National Conference.

NZMOH (2002). Dementia in New Zealand: improving quality in residential care A report to the Disability Issues Directorate Ministry of Health.

NZMOH (2004). Ageing New Zealand and Health and Disability Services 2001-2021: Background information. Internal responses to ageing populations. from http://www.moh.govt.nz/moh.nsf/49ba80c00757b8804c256673001d47d0/be640007ef 8cf592cc256f73000ff0a0?OpenDocument.

NZMOH (2011). Mental Health and Addiction Services for Older People and Dementia Services: Guideline for District Health Boards. from http://www.moh.govt.nz/moh.nsf/indexmh/mental-health-addiction-services-olderpeople-and-dementia.

NZSM, M. T. D. (2011). Ethical Guidelines for NZSM526 Research Projects. Unpublished Ethical guidelines. New Zealand School of Music.

NZSM., M. T. D. (2011). Ethical Guidelines for NZSM526 Research Projects. Unpublished Ethical guidelines. New Zealand School of Music.

Pollack, N. J., \& Namazi, K. H. (1992). The effect of music participation on the social behaviour of Alzheime's diesease patients. Journal of Music Therapy, 29(1), 54-67

Powell, H. (2006). Evaluation of music therapy with older people, including those with dementia, in community locations. British Journal of Music Therapy, The voice of experience.

Remington, R. (2002). Calming music and hand massage with agitated elderly. Nursing Research, 51(5), 317-323. 
Ridder, H. M., \& Aldridge, D. (2005). Individual Music Therapy with Persons with Frontotemporal Dementia -- Singing Dialogue. Nordic Journal of Music Therapy, 14(2), 91 - 106.

Ridder, H. M., (2003). Singing dialogue Music therapy with persons in advanced stages of dementia. Unpublished A case study research design, Aalborg Universitet.

Ridder, H. M. (2004). When dialogue fails. music therapy with elderly with neurological degenerative diseases.

Ridder, H. M. (2011). How Can Singing in Music Therapy Influence Social Engagement for People with Dementia. In F. Baker, Uhligh, Sylka., and Austin, Diane. (Ed.), Voicework in Music Therapy: Research and Practice: Jessica Kingsley Publishers, 2011.

Ridder, H. M., Wigram, T., \& Ottesen, A., M. (2009). A pilot study on the effects of music therapy on frontotemporal dementia - developing a research protocol. Nordic Journal of Music Therapy, 18(2), 103 - 132.

Sherratt, K., Thornton, A., \& Hatton, C. (2003). Emotional and behavioural responses to music in people with dementia: an observational study. Aging \& Mental Health, 8(3), $233-241$.

Sambandham, M., \& Schirm, V. (1995). Music as a nursing intervention for residents with Alzheimer's disease in long-term care. Geriatric Nursing, 16(2), 79-83.

Sherratt, K., Thornton, A., \& Hatton, C. (2004). Music interventions for people with dementia: A review of the literature. Aging and Mental Health, 8(1), 3-12.

Simpson, F. (2000). Creative Music Therapy, A Last Resort? In D. Aldridge (Ed.), Music Therapy in Dementia Care, More New Voices (pp. 167 -183). London and Philadelphia: Jessica Kingsley Publishers.

Svansdottir, H. B., \& Snaedal, J. (2006). Music therapy in moderate and severe dementia of alzheimer's type: a case - control study. [Journal]. International Psychogeriatrics, 18(4).

Tomaino, C., . M. (1999). Active Music Therapy Approaches for Neurologically Impaired Patients. In C. Dileo (Ed.), Music Therapy \& Medicine: Theoretical and Clinical Applications. Silver Stream: The American Music Therapy Association, Inc.

Wall, M., \& Duffy, A. (2010). The effects of music therapy for older people with dementia. British Journal of Nursing, 19(2), 7.

Wigram, T. (2004). Improvisation: methods and techniques for music therapy clinicians , educators and students. England: Jessica Kingsley Publishers Ltd.

Wills, T., \& Day, M. R. (2008). Valuing the person's story: Use of life story books in a continuing care setting. Clinical Interventions in Aging, 3(3), 10. 


\section{LIST OF APPENDICES}

Page

1. Kitwood's definition of needs

2. Deductive process of data

3. Information sheet for individual/family

4. Consent sheet for individual/family

5. Quality of Interaction Schedule 


\section{Kitwood's definition of needs:}

Comfort:

"This word, in its original sense, carries meanings of tenderness, closeness, the soothing of pain and sorrow, the calming of anxiety, the feeling of security which comes from being close to another. To comfort another person is to provide a kind of warmth and strength which might enable them to remain in one piece when they are in danger of falling apart. In dementia the need for comfort is likely to be especially great when a person is dealing with a sense of loss, whether that arises from bereavement, the failing of abilities, or the ending of a long-established way of life. It has urgent moments, for example in times of parting, and it is also a continuing theme. The heightened sexual desire that is felt by some people with dementia may be interpreted, in part at least, as a manifestation of this need.” (1997)

\section{Attachment:}

"Ours is a highly social species, and this is clearly shown in the forming of specific bongs or attachments. The pioneer of research in this field, John Bowlby (1979) claimed that bonding is a cross-cultural universal, and instinct-like in its nature. He suggested that it creates a kind of safety net, particularly in the first years of life, when the world is full of uncertainty. Without the reassurance that attachments provide it is difficult for any person, of whatever age, to function well. The loss of a primary attachment undermines the sense of security, and if several bonds are broken within a short time the effect can be devastating. There is every reason to suppose that the need for attachment remains when a person has dementia; indeed it may be as strong as in early childhood. Life is overshadowed by new uncertainties and anxieties, and some of the good memories from past secure attachments may be lost. Bere Miesen (1992), who has studied this topic in some detail, suggests that people with dementia are continually finding themselves in situations that they experience as 'strange', and that this powerfully activates the attachments need.” (1997)

\section{Inclusion:}

"The social nature of human life has another aspect, related to the fact that we evolved as a species designed for life within face-to-face groups. To be part of the group was essential for survival, and in some cultures temporary exclusion was a form of severe punishment. The need for inclusion comes poignantly to the surface in dementia, perhaps in so-called attention-seeking behaviour, in tendencies to cling or hover, of in various forms of protest and disruption. In the ordinary settings of everyday life it is still very rare for people with mental impairments to be included with ease. Very often the social life of those who have dementia tends to dwindle away, as the dialectical interplay between neurological impairments and social psychology takes its course. In many old-style residential settings the need for inclusion was not 
addressed at all, as people were left together, but profoundly alone. Individualized care plans and packages, while a vast improvement, sometimes overlook this issue. If the need is not met a person is likely to decline and retreat, until life is lived almost entirely within the bubble of isolation that Tessa Perrin has described (p. 25) (sic.). When, however, the need is met, a person may be able to 'expand' again, recognized as having a distinct place in the shared life of a group.” (1997)

Occupation:

"To be occupied means to be involved in the process of life in a way that is personally significant, and which draws on a person's abilities and powers. The opposite is a state of boredom, apathy and futility. The roots of occupation lie in infancy, as a child acquires the sense of agency: the realization that it is possible to evoke a response from others, and make things happen in the world. A person might be occupied in the company of others, or in solitude, in obvious action, in reflection or in relaxation. Often occupation involves having some kind of project, whether in work or leisure; it might, however, simply consist of play. If people are deprived of occupation their abilities begin to atrophy, and self-esteem drains away. The need for occupation is still present in dementia; it is clearly manifested, for example, when people want to help, or eagerly take part in activities and outings. It requires a great deal of skill and imagination to meet the need without imposing false solutions, crude and ready-made. The more that is known about a person's past, and particularly their deepest sources of satisfaction, the more likely it is that solutions will be found." (1997)

Identity:

"To have an identity is to know who one is, in cognition and in feeling. It means having a sense of continuity with the past; and hence a 'narrative', a story to present to others. It also involves creating some kind of consistency across the different roles and contexts of present life. To some extent identity is conferred by others, as they convey to a person subtle messages about his or her performance. How each individual constructs his or her identity is unique. In the 'old culture' of dementia care many of a person's sources of identity were taken away, particularly through the extremes of institutionalization and the removal of all contact with the past. We are learning now that much can be done to maintain identity in the face of cognitive impairment. Two things seem to be essential (Kitwood 1997a). The first is knowing in some detail about each individual's life history; even if a person cannot hold on to his or her own narrative identity, due to loss of memory, it can still be held by others. The second is empathy, through which it is possible to respond to a person as Thou, in the uniqueness of his or her being.” (1997) 


\section{Colour Codes and Summaries of Kitwood's Model of Needs used in deductive} stage of data analyses of data:

- Love - Central need.

Comfort - Kitwood defines it in its original sense and then particularly to those with dementia. Comfort is likely to be especially important when a person is dealing with a 'sense of loss'(bereavement, failing abilities, ending of long established way of life). Comforting a person provides a kind of warmth and strength which might enable them to remain in one place when they are in danger of falling apart.

- It soothes (pain and sorrow)

- Calms anxiety

- Provides security (through closeness to another person)

- Gives support, warmth, strength (for remaining in one piece)

Particular features of dementia:

- $\quad$ The need for comfort is intense in moments of parting and heightened sexuality

Attachment - provides reassurance for a person who may have had lost several bonds of security. Attachment is especially important for those suffering the uncertainties of dementia. People with dementia may continually find themselves in experiences that are 'strange' and this powerfully activates the attachment need. Previous good memories from past secure attachments may be lost. The loss of primary attachment undermines a sense of security, and makes it difficult for any person to function well.

- Reassures

- Holds

- Provides a bond to hold onto, that is safe and secure 


\section{- Assures}

Inclusion - is needed for those without a way to be socially active, dementia often reduces the dialectical interplay between neurological impairment and social psychology which causes a person to become more socially isolated. Inclusion is needed so the natural social needs of a person are met. If inclusion is lacking for a person with dementia, so-called attention seeking behaviours may surface (clinging, hovering, various forms of protest and disruption).

- Socialising/engagement

- $\quad$ Contributing to something

- Part of society

- Recognition as part of group

Occupation - means to be involved in the process of life in a way that it personally significant, drawing on person's abilities and powers. The roots of occupation lie in infancy and sense of agency. A person can be occupied with others or in solitude (reflection, relaxation). The opposite of occupation is boredom, apathy and futility, self-esteem drains away. Skill and imagination is needed when meeting the need for people with dementia so you are not imposing false solutions, crude and ready-made. The more that is known about the person's past and the things that have brought them the deepest satisfaction the more likely it is that solutions are found.

- Involved in a project/activity or play

- Giving a purpose to a person’s life

- Exemplifies unique abilities/powers

- Significance to life (having 'Goals' in life)

- $\quad$ Self esteem/Empowerment? 
Identity - is to know who one is, in cognition and feeling. It means you have continuity with the past, and have a "narrative" a story to present others. Much can be done to maintain identity in the face of cognitive impairment. Two things are important to do this. First is knowing in some detail each individual's life history, even if a person cannot hold on to their own narrative due to loss of memory, it can be held for them by others. The second is empathy, so they can be responded to like the unique person they are.

- Gives knowledge of self, cognitively and or in feeling/emotionally

- Maintains personhood (as the unique individuals they are)

- Identities can be held for them so they continue to be treated with the same degree as respect and acknowledgement as other individuals who can still remember and communicate their histories. 


\section{Information Sheet}

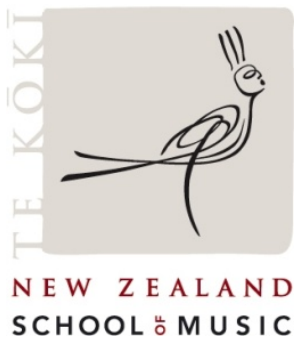

MUSIC THERAPY PROGRAMME (MMUSTher)

Information sheet for individual consent

Thesis Title:

\section{The Relationship between Kitwood's Model of Needs and a Student's Music Therapy Practice in an Assessment Unit for Older Persons with Mental Health Issues}

Dear (Family/guardian),

My name is Rani Allan and I am a second year master's of music therapy student undertaking a clinical placement at I I have been working with the unit to provide music therapy in the ward three days a week since February. As part of my training I am required to research an aspect of my practice.

The purpose of the research is to improve my learning and to inform other music therapy students and practitioners of the particular issues and joys involved in the work. With informed consent from all affected parties, I will write on an aspect of music therapy work that particularly interests me.

Because of my placement I am especially interested in a person-centred care theory that links ideas of comfort, identity, occupation, attachment and inclusion to more appropriate levels of care. I am writing to you because I would like to use data that was collected as part of my clinical practice, and which relates to your family member, in my research project. The data will be analysed along with data from other sources, to answer my research questions and illustrate illuminating aspects of practice.

As per the ethical guidelines that have been set out by the New Zealand School of Music, all identifiable information such as name(s) and location of facility shall be removed from the data to ensure anonymity. However it is important to note that that the type of facility (i.e. mental health unit for older persons) but not the name of the unit, is an integral part of my research, and will therefore need to be included. It is also important to know that the music therapy community in New Zealand is small, and although real names and that of the facility will not be included in any written material there is a possibility that it might be identified.

This preliminary communication is to ask permission for me to consider using some of the clinical data that I have collected as part of my normal practice while working at $\square$ so that I might illustrate the integral and important themes that have arisen in the research, 
already the therapy that I have shared with your family member has not only been insightful of mental health issues but also provided wonderful humanistic opportunities to share stories, learn about what is sought in these times of life and also search for better ways to provide music therapy in this setting.

Should you agree to me to using my clinical notes, this data would be stored and used on a locked laptop and after the research has been completed would be locked and stored in the Music Therapy department of the New Zealand School of Music.

Please be aware that you are under no obligation to give your permission for your family member's data to be used for research purposes. If you decide to allow it to be used, you have the right to:

- ask any questions about the study at any time until it is completed;

- provide information on the understanding that your name or family members will not be used unless you give permission to the researcher;

- be given access to a summary of the project findings when it is concluded.

Please also note that this project has been reviewed and approved by the New Zealand School of Music Postgraduate committee. The Chairs of Massey University Human Ethics and Health and Disability Ethics Committees have given generic approval for music therapy students to conduct studies of this type. The music therapy projects have been judged to be low risk and, consequently, are not separately reviewed by any Human Ethics Committees. The supervisor named below is responsible for the ethical conduct of this research. If you have any concerns about the conduct of this research, please contact the supervisor or, if you wish to raise an issue with someone other than the student or supervisor, please contact Professor John O’Neill, Director, Research Ethics, telephone 06350 5249, email: humanethics@massey.ac.nz”.

If you would like any further information please feel free to contact either myself or my research supervisor Sarah Hoskyns at any time to discuss any issues or questions you might have.

Kind Regards,

Maharani (Rani) Allan

Sarah Hoskyns

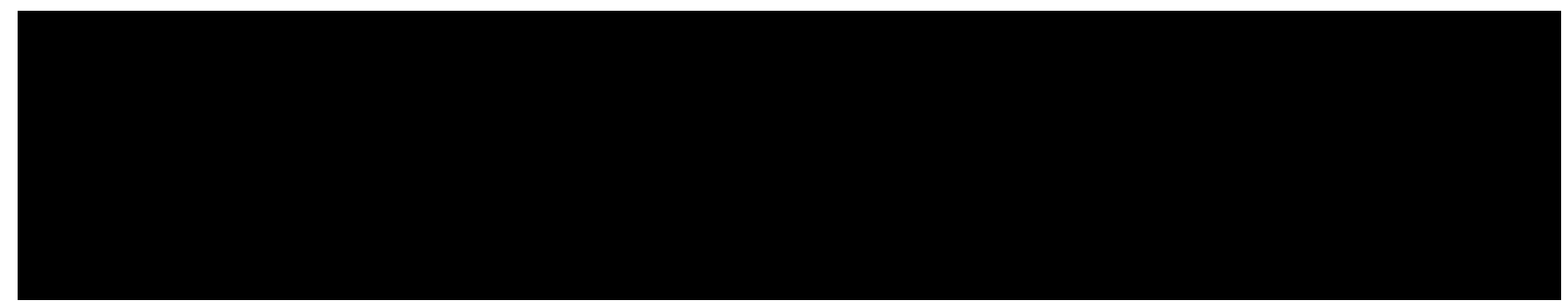




\section{Consent Sheet}

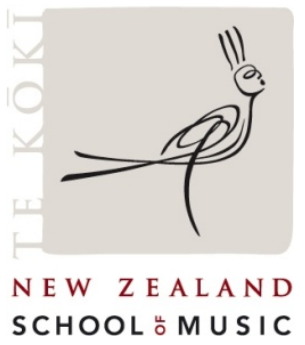

MUSIC THERAPY PROGRAMME (MMUSTher)

Consent for secondary data analysis for individual from family/guardian

Thesis Title:

\section{The Relationship between Kitwood's Model of Needs and a Student's Music Therapy Practice in an Assessment Unit for Older Persons with Mental Health Issues}

I understand that as part of the requirements for her Music Therapy Clinical Placement Maharani (Rani) Allan will be completing an in-depth study of her normal practice while in placement which will cumulate in an end of year thesis exegesis.

I have read the Information Sheet and have had the details of the study explained to me. My questions have been answered to my satisfaction, and I understand that I may ask further questions at any time.

I understand that clinical information about the participant may be shared with the student's Music Therapy Supervisor and examiners at the New Zealand School of Music, with Supporting Music Therapists and other professionals and students enrolled in the Music Therapy $2^{\text {nd }}$ year programme.

I understand that the clinical and background information shared as above will remain confidential and will not be shared with anyone outside the above group of persons without the expressed permission from the participant.

I understand that an exegesis will be written up and presented at the end of the study as a summative requirement of the placement and master's programme. A transcript of this presentation will be submitted to the music therapy department and will be read and reviewed by examiners both internal and external to the New Zealand School of Music.

I understand that if I request it, I can receive a copy of this exegesis after it has been completed and examined following the conclusion of the placement.

I understand and agree to my family member's clinical notes being used for reflection and analysis for research purposes. 
I understand and agree to the data being used in this study under the conditions set out in the Information Sheet.

I (please print) have read and understood the information provided and give consent for Maharani (Rani) Allan to review her clinical notes on this participant and use the information to illustrate aspects of practice in her exegesis.

Signed Family representative 


\section{Quality of Interaction Schedule}

1. Recognition - Here a man or a woman who has dementia is being acknowledged as a person, known by name, affirmed in his or her own unique-ness, recognition may be achieved in a simple act of greeting, or in careful listening over a longer period - perhaps as a person describes an earlier part of their life. Recognition, though, is never purely verbal, and it need not involve words at all. One of the profoundest acts of recognition is simply the direct contact of the eyes.

2. Negotiation - The characteristic feature of this type of interaction is that people who have dementia are being consulted about their preferences, desires and needs, rather than being conformed to others' assumptions. Skilled negotiation takes into account the anxieties and insecurities that often pervade the lives of people with dementia, and the slower rate at which they handle information. Negotiation gives even highly dependent people some degree of control over the care that they receive and puts power back into their hands.

3. Collaboration - Here we gain a glimpse of two or more people aligned on a shared task, with a definite aim in view. The true meaning of collaboration is 'working together', and this may be literally the case; as, for example, in doing the same household chores. Less obviously, it can occur in the contexts of personal care such as getting dressed, having a bath or going to the toilet. The hallmark of collaboration is that care is not something that is 'done to' a person who is in a passive role; it is a process in which their own initiative and abilities are involved. 
4. Play - Whereas work is directed towards a goal, play in its purest form has no goal outside the activity itself. It is simply an exercise in spontaneity and selfexpression, an experience that has value in itself. Because of the sheer pressures of survival, and the disciplines of work, many adults have only poorly developed abilities in this area. A good care environment is one which allows these abilities to grow.

5. Timalation - This term refers to forms of interaction in which the prime modality is sensuous or sensual with the intervention of concepts and intellectual understanding; for example through aromatherapy and massage. The word itself is a neologism, derived from the Greek word timao (I honour, and hence I do not violate personal or moral boundaries) and stimulation (with its connotations of sensory arousal). The significance of this kind of interaction is that it can provide contact, reassurance and pleasure, while making very few demands. It is thus particularly valuable when cognitive impairment is severe.

6. Celebration - The ambiences here is expansive and convivial. It is not simply a matter of special occasions, but any movement at which life is experienced as intrinsically joyful. Many people who have dementia, despite their suffering, retain the capacity to celebrate; perhaps it is even enhanced as the burdens of responsibility disappear. Celebration is the form of interaction in which the division between caregiver and cared-for comes nearest to vanishing completely; all are taken up into a similar mood. The ordinary boundaries of ego have become diffuse, and selfhood has expanded. In some mystical traditions, this is the meaning of spirituality. 
7. Relaxation - Of all forms of interaction, this is the one that has the lowest level of intensity, and probably also the slowest pace. It is possible, of course, to relax in solitude, but many people with dementia, with their particularly strong social needs, are only able to relax when others are near them, or in actual bodily contact.

8. Validation - This term has a long history in psychotherapeutic work, going back some time before Naomi Feil made it famous in dementia care (e.g. Laing 1967). The literal meaning is to make strong or robust; to validate the experience of another is to accept the reality and power of that experience, and hence its 'subjective truth'. The heart of the matter is acknowledging the reality of a person's emotions and feelings, and giving a response on the felling level. Validation involves a high degree of empathy, attempting to understand a person's entire frame of reference, even if it is chaotic or paranoid, or filled with hallucinations. When our experience is validated we feel more alive, more connected, more real; there is every ground for supposeing that this is true in dementia as well.

9. Holding - This, of course, is a metaphor, derived from the physical holding of a child who is in distress. To hold, in a psychological sense, means to provide a safe psychological space, a 'container'; here hidden trauma and conflict can be brought out; areas of extreme vulnerability exposed. When the holding is secure a person can know, in experience, that devastating emotions such as abject terror of overwhelming grief will pass, and not cause the psyche to disintegrate. Even violent anger or destructive rage directed for a while at the person who is doing 
the holding, will not drive that person away. As in the case of childcare, psychological holding in any context may involve physical holding too.

10. Facilitation - At its simplest this means enabling a person to do what otherwise they would not be able to do, by providing those parts of the action - and only those - that are missing. Facilitation of this kind merges into what I have called collaboration. The more truly psychotherapeutic interaction occurs when a person's sense of agency has been seriously depleted, or when action schemata have largely fallen apart. Perhaps all that is left is a hesitant move towards an action, or gesture. The task of facilitation is to enable interaction to get started, to amplify it and to help the person gradually fill it out with meaning. When this is done well there is a great sensitivity to the possible meanings in a person's movements, and interaction proceeds at a speed that is slow enough to allow meaning to develop. 
Figure 2.

Mind-map of analysis process:

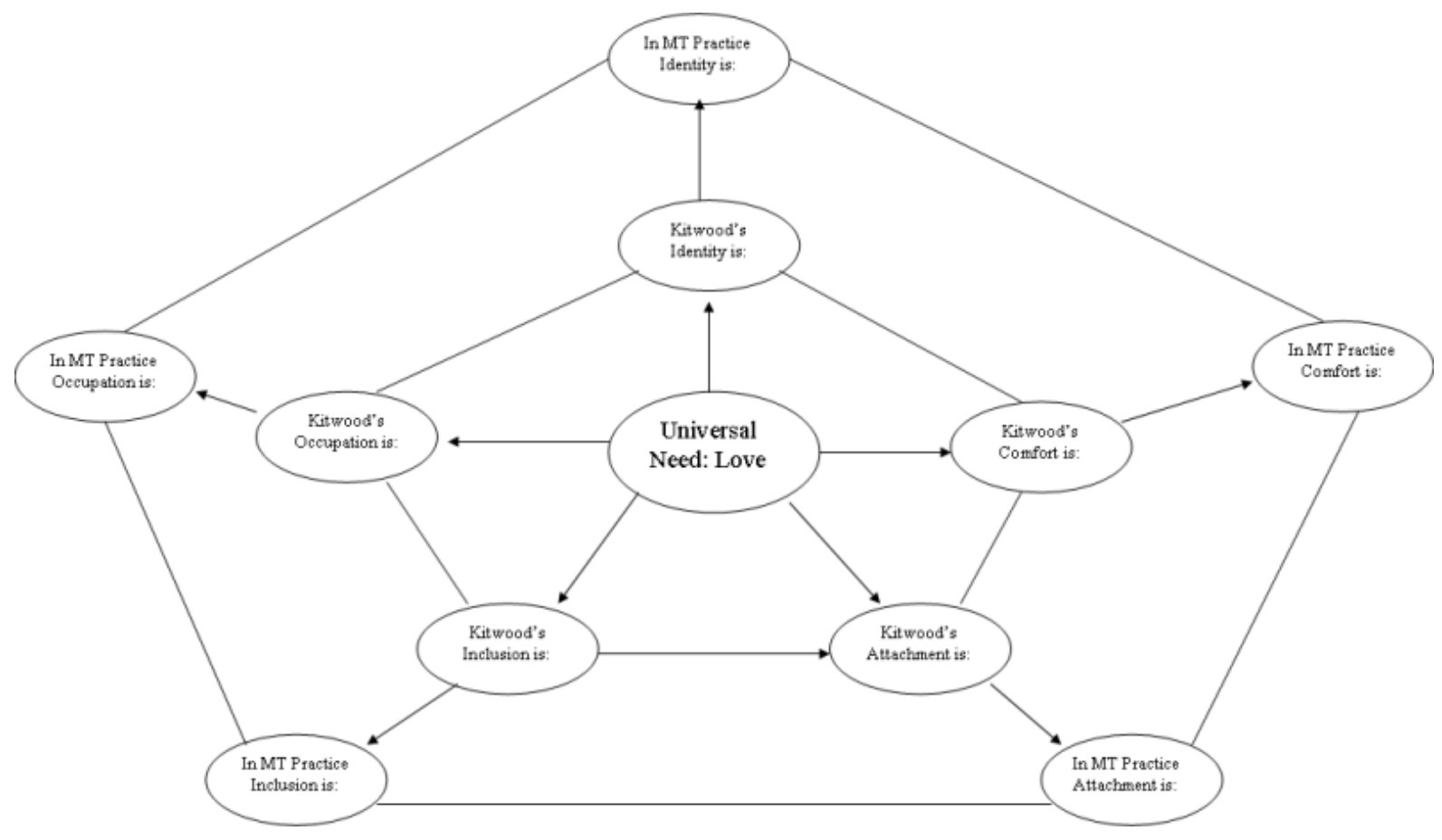


Table 2.

Braun and Clarke's (2006) Phases of Thematic Analysis:

Table 1: Phases of Thematic Analysis

\begin{tabular}{ll}
\hline Phase & Description of the process \\
\hline 1. Familiarising yourself with your data: & $\begin{array}{l}\text { Transcribing data (if necessary), reading and re- } \\
\text { reading the data, noting down initial ideas. }\end{array}$ \\
\hline 2. Generating initial codes: & $\begin{array}{l}\text { Coding interesting features of the data in a } \\
\text { systematic fashion across the entire data set, } \\
\text { collating data relevant to each code. }\end{array}$ \\
\hline 3. Searching for themes: & $\begin{array}{l}\text { Collating codes into potential themes, gathering all } \\
\text { data relevant to each potential theme. }\end{array}$ \\
\hline 4. Reviewing themes: & $\begin{array}{l}\text { Checking in the themes work in relation to the coded } \\
\text { extracts (Level 1) and the entire data set (Level 2), } \\
\text { generating a thematic 'map' of the analysis. }\end{array}$ \\
\hline 5. Defining and naming themes: & $\begin{array}{l}\text { Ongoing analysis to refine the specifics of each } \\
\text { theme, and the overall story the analysis tells; } \\
\text { generating clear definitions and names for each } \\
\text { theme. }\end{array}$ \\
\hline 6. Producing the report: & $\begin{array}{l}\text { The final opportunity for analysis. Selection of vivid, } \\
\text { compelling extract examples, final analysis of } \\
\text { selected extracts, relating back of the analysis to the } \\
\text { research question and literature, producing a } \\
\text { scholarly report of the analysis. }\end{array}$ \\
\hline
\end{tabular}

